\title{
Microbiota and Ocular Diseases
}

\author{
Wei Xue ${ }^{1}$, Jing Jing $\mathrm{Li}^{1}$, Yanli Zou ${ }^{1,2}$, Bin Zou ${ }^{1}$ and Lai Wei ${ }^{1 *}$ \\ 1 State Key Laboratory of Ophthalmology, Sun Yat-sen University, Guangzhou, China, ${ }^{2}$ Department of Ophthalmology, \\ Affiliated Foshan Hospital, Southern Medical University, Foshan, China
}

\section{OPEN ACCESS}

Edited by:

Hiroshi Eguchi,

Kindai University, Japan

Reviewed by:

Kamal Kumar Gupta,

University of Delhi, India

Mihaela Gadjeva,

Harvard Medical School, United States

Ming-Tse Kuo,

Kaohsiung Chang Gung Memorial Hospital, Taiwan

*Correspondence:

Lai Wei

weil9@mail.sysu.edu.cn

Specialty section:

This article was submitted to Microbiome in Health and Disease,

a section of the journal

Frontiers in Cellular and

Infection Microbiology

Received: 16 August 2021 Accepted: 06 October 2021

Published: 21 October 2021

Citation:

Xue W, Li JJ, Zou Y, Zou B and Wei L (2021) Microbiota and Ocular Diseases.

Front. Cell. Infect. Microbiol. 11:759333. do: 10.3389/fcimb.2021.759333
Recent advances have identified significant associations between the composition and function of the gut microbiota and various disorders in organ systems other than the digestive tract. Utilizing next-generation sequencing and multiomics approaches, the microbial community that possibly impacts ocular disease has been identified. This review provides an overview of the literature on approaches to microbiota analysis and the roles of commensal microbes in ophthalmic diseases, including autoimmune uveitis, agerelated macular degeneration, glaucoma, and other ocular disorders. In addition, this review discusses the hypothesis of the "gut-eye axis" and evaluates the therapeutic potential of targeting commensal microbiota to alleviate ocular inflammation.

Keywords: gut microbiome, gut-eye axis, ophthalmic diseases, multiomics, microbial therapeutics

\section{INTRODUCTION}

Dysbiosis in the gut microbiota has been linked to multiple gastrointestinal disorders, such as inflammatory bowel disease, irritable bowel syndrome, and celiac disease (Rajilić-Stojanović et al., 2015; Bernstein and Forbes, 2017; Chibbar and Dieleman, 2019). Recent decades have seen ample evidence documenting a much broader stimulatory/regulatory role of the gut microbiota in disorders involving organ systems other than the digestive tract (Jangi et al., 2016; Scher et al., 2016).

The eye and brain are two organs remote from the intestines and considered unrelated to any effects exerted by the gut microbiota. However, the emergence of microbiota as a crucial regulator of brain function has led to increasing attention to the communication that occurs between the gut microbiota and the central nervous system (Cryan et al., 2019). Eye-related diseases and their associations with the gut microbiome are the focus of the current review. The gut is occupied by trillions of microbes and thousands of species suitable for high-throughput sequencing technologies. Utilizing next-generation sequencing and multiomics approaches, the microbial community that possibly impacts ocular disease has been identified. Here, we review the common methods used to study the microbiome, with a particular focus on several meta-approaches and animal models. We also discuss the "gut-eye axis" and the interrelationship between intestinal/ocular microbiota and several ophthalmic diseases, such as autoimmune uveitis, age-related macular degeneration (AMD), glaucoma, and other ocular disorders. Finally, the therapeutic potential of targeting commensal microbiota is evaluated. 


\section{INFLUENCES OF THE GUT MICROBIOME AND ANALYSIS APPROACHES}

\subsection{Gut Microbiome}

The gut microbiome has well-defined roles in digestion, production of vitamins, synthesis of short-chain fatty acids (SCFAs) (such as acetate, propionate, and butyrate), protection against pathogenic bacteria, and development of the host immune system. In addition, the gut microbiome helps preserve the homeostasis of several T-cell populations in the gut, comprising regulatory T cells (Tregs), T helper 1 (Th1) cells and 17 (Th17) cells, which are vital in hosting an immune response against pathogens (Kho and Lal, 2018). These effects might be mediated by the microbes themselves or indirectly by their metabolites. For example, the SCFAs produced by some intestinal microbes, such as Bacteroides, can regulate Treg and Th17 cells in the intestine, circulation, and extraintestinal tissues (Zeng and Chi, 2015).

The human gut microbiota is composed of 6 main phyla: Firmicutes, Bacteroidetes, Actinobacteria, Fusobacteria, Verrucomicrobia, and Proteobacteria (The Human Microbiome Project Consortium, 2012). Of these, Firmicutes and Bacteroidetes represent $70-90 \%$ of the gut microbiota (Kho and Lal, 2018). In a healthy human, the gut bacterial microbiome maintains a delicate balance between "good or beneficial" (probiotic and anti-inflammatory) and "bad or harmful" (pro-inflammatory and pathogenic) bacteria. Increases in the abundance of proinflammatory bacteria, e.g., Escherichia coli, and decreases in the abundance of antiinflammatory bacteria, e.g., Faecalibacterium prausnitzii, are closely related to autoimmune intestinal diseases, including Crohn's disease and ulcerative colitis (Hornef and Pabst, 2016; Viladomiu et al., 2017). Disturbances in the gut microbiota have been implicated in a wide range of diseases, including irritable bowel syndrome (Rajilić-Stojanović et al., 2015), inflammatory bowel disease (Sheehan et al., 2015), obesity (Aron-Wisnewsky and Clément, 2016), diabetes (Karlsson et al., 2013; Forslund et al., 2015; Tai et al., 2015), multiple sclerosis (Jangi et al., 2016), rheumatoid arthritis (Scher et al., 2016), graft-versus-host disease (Mathewson et al., 2016), and neurodegenerative diseases (Ghaisas et al., 2016), many of which are associated with serious ophthalmic sequelae.

\subsection{Approaches to Microbiome Analysis}

A crucial step in traditional microbiological studies is the isolation of microorganisms from samples while avoiding contamination from human handling as much as possible. There are multiple options for modern "-omics" studies. Here, we discuss several analytical approaches to microbiome studies in the context of ocular diseases.

Traditionally, isolation and direct culture have been used for microbial investigations, and these strategies are still used today. However, culture-based techniques can only be used to characterize a small percentage of the actual microbial populations in a sample because they are limited by the phenotypic characteristics of microbes, for example, the ability of microbes in a sample to proliferate in or on a specified growth medium under a specified growth condition (SchabereiterGurtner et al., 2001; Hori et al., 2008; Fernández-Rubio et al., 2010; Ozkan et al., 2017). Meantime, combining quantitative PCR with negative staining transmission electron microscopy is an effective means of identifying microbial populations (Deng et al., 2021). In fact, cultivated bacteria represent only half of the bacterial phyla thus far Schloss (Schloss and Handelsman, 2004)

Given the widespread use of next-generation sequencing technologies, the high-throughput analysis of microbial communities has become a much lower cost and less timeconsuming approach that allows researchers to achieve a more complete understanding of the composition of commensal communities. Since it is difficult to study underrepresented bacteria, such as those of the eye, by traditional methods, this advance has been especially crucial for studying ocular communities (Stein-Streilein, 2008; Cone and Pais, 2009). 16S/ 18S/ITS gene amplicons and shotgun sequencing are usually used to analyze microbial populations (Clarridge, 2004; Rausch et al., 2019).

\subsubsection{Multiomics Approach}

The multiomics approach has been applied to sort out the molecular interactions in cells and tissues in complex disease settings. Here, we broadly classify the multiomics approach into metagenomics, metatranscriptomics, metaproteomics, and metametabolomics and discuss recent discoveries in ocular diseases utilizing these approaches (Table 1).

\subsubsection{Metagenomics}

Metagenomics is used to sequence the genomes of microbes, e.g., archaea, bacteria, viruses, fungi, parasites and their entire functional profiles, present in a given sample (Lorenzon et al., 2018; Almeida et al., 2019; Coker et al., 2020; Daliri et al., 2020; Gregory et al., 2020; Nagpal et al., 2020). Two approaches are commonly used, namely, marker gene analysis and shotgun sequencing. These two methods allow for the analysis of genes of interest and the analysis of detailed genetic and taxonomic information, respectively. Metagenomic profiles have been characterized in Behcet's disease (BD) (Ye et al., 2018) and Vogt-Koyanagi-Harada disease (VKHD) patients (Ye et al., 2020). These two groups of patients show distinctly abundant microbial species compared with controls. Interestingly, by using metagenomic sequencing, our group provided preliminary evidence that the intraocular microbiota signature might also be disease-specific in ocular diseases such as glaucoma and AMD (Deng et al., 2021). Veillonella have been found as the predominant genus in patients of chronic dacryocystitis through metagenomic sequencing (Eguchi et al., 2017a).

Shotgun sequencing profiles may present information about the potential function(s) of an entire microbial community at the gene level based on databases of microbial genomes with known sequences, yet the information yielded by this method may not accurately represent what is happening in the gut at a given time (Emerson et al., 2017). This is supported by studies of taxonomic abundance that do not correspond to transcriptional activities 
TABLE 1 | Advantages and disadvantages of the multiomics approaches.

\begin{tabular}{|c|c|c|c|}
\hline $\begin{array}{l}\text { Multiomics } \\
\text { approach }\end{array}$ & Advantages and Disadvantages & Literature & \\
\hline \multirow[t]{5}{*}{ Metagenomics } & $\begin{array}{l}\text { Reveals in revealing the low abundant cultivable and non-cultivable } \\
\text { microorganisms in a given sample }\end{array}$ & $\begin{array}{l}\text { Abundant microbial species increased in } \mathrm{BD} \text { and } \\
\text { VKHD patients }\end{array}$ & $\begin{array}{l}\text { (Ye et al., 2018; Ye } \\
\text { et al., 2020) }\end{array}$ \\
\hline & $\begin{array}{l}\text { Biases in amplifications due to equal affinities of primers in marker } \\
\text { gene analysis }\end{array}$ & $\begin{array}{l}\text { Identifying the intraocular microbiota signature in } \\
\text { glaucoma and AMD }\end{array}$ & (Deng et al., 2021) \\
\hline & Inconformity of taxonomic abundance and transcriptional activities & $\begin{array}{l}\text { Veillonella as the predominant genus in patients of } \\
\text { chronic dacryocystitis }\end{array}$ & $\begin{array}{l}\text { (Eguchi et al., } \\
\text { 2017a) }\end{array}$ \\
\hline & Lack of abundance of gene functional annotation database & $\begin{array}{l}\text { The abundance of bacillus and Enterococcus } \\
\text { faecium in MGD }\end{array}$ & (Zhao et al., 2020) \\
\hline & & $\begin{array}{l}\text { Microbiological differences between conjunctival } \\
\text { swabs and lid }\end{array}$ & $\begin{array}{l}\text { (Zysset-Burri et al., } \\
\text { 2021) }\end{array}$ \\
\hline \multirow[t]{4}{*}{ Metatranscriptomics } & $\begin{array}{l}\text { Provides high-throughput microbial transcriptome information of } \\
\text { cultivable and non-cultivable species }\end{array}$ & $\begin{array}{l}\text { Glucorhamnan from Ruminococcus gnavus induces } \\
\text { dendritic cells to secret TNF } \alpha \text { in with Crohn's } \\
\text { disease }\end{array}$ & (Henke et al., 2019) \\
\hline & rRNA contamination & & \\
\hline & No standard methods for RNA acquisition & $\begin{array}{l}\text { Ruminococcus gnavus regulars intestinal barrier } \\
\text { function }\end{array}$ & $\begin{array}{l}\text { (Graziani et al., } \\
\text { 2016; Luissint et al., } \\
\text { 2016) }\end{array}$ \\
\hline & $\begin{array}{l}\text { Differences in ribosome binding ability to mRNA leads to affect the } \\
\text { analysis of the functional protein }\end{array}$ & $\begin{array}{l}\text { Basic metabolism are severely impaired in the } \\
\text { duodenal microbiota of obese patients }\end{array}$ & $\begin{array}{l}\text { (Granata et al., } \\
\text { 2020) }\end{array}$ \\
\hline \multirow[t]{4}{*}{ Metaproteomics } & $\begin{array}{l}\text { Allows for large-scale identification and quantification of microbial } \\
\text { proteins, and reveals the function and metabolic pathway of the } \\
\text { microbiota }\end{array}$ & $\begin{array}{l}\text { Phylogenetic changes in bacteria in intestinal } \\
\text { inflammation }\end{array}$ & $\begin{array}{l}\text { (Mayers et al., } \\
\text { 2017) }\end{array}$ \\
\hline & Contamination from host and undigested proteins & & \\
\hline & No standardized method for protein preparation & & \\
\hline & Lack of the protein database for identification & & \\
\hline \multirow[t]{2}{*}{ Metametabolomics } & $\begin{array}{l}\text { Creates profiles of microbial metabolites and reveals metabolic } \\
\text { patterns of the microbiota } \\
\text { No standardized method for metabolites preparation }\end{array}$ & $\begin{array}{l}\text { Biomarkers of distinguishing AAU progression and } \\
\text { treatment response }\end{array}$ & $\begin{array}{l}\text { (Guo et al., 2014; } \\
\text { Luissint et al., 2016) }\end{array}$ \\
\hline & The uncertain origin of the microbial metabolites & $\begin{array}{l}\text { Detrimental co-metabolites of determining specific } \\
\text { bacterial genomes in genetic and simple obesity in } \\
\text { children }\end{array}$ & $\begin{array}{l}\text { (Heintz-Buschart } \\
\text { et al., 2016) }\end{array}$ \\
\hline
\end{tabular}

(Abu-Ali et al., 2018; Jia et al., 2019; Granata et al., 2020). Utilizing this method, distinct meibum microbial communities were identified in patients with meibomian gland dysfunction and in healthy controls, indicating different immune evasive virulence of the meibum microbiota (Zhao et al., 2020). The ocular surface microbiome identified by metagenome shotgun sequencing have recently been associated with the tear proteome, suggesting a role in human immune defense (Zysset-Burri et al., 2021).

\subsubsection{Metatranscriptomics}

Metatranscriptomics exploits RNA sequences to reveal the presence and quantity of microbial RNA in a biological sample at a given time. Shotgun metatranscriptomics can answer the question of what microbes are doing "right then" in an ecosystem (Franzosa et al., 2014). Analyzing their RNA provides clues to determining their metabolic activities in response to stress and how such alteration in metabolic activity influences host phenotypes in healthy or diseased conditions (Daliri et al., 2021).

Ruminococcus gnavus, a prevalent member of the human gut microbes, has been found to produce an inflammatory polysaccharide, i.e., glucorhamnan, which induces dendritic cells to secrete TNFo in patients with Crohn's disease (Henke et al., 2019). The same bacterial species has also been reported to fortify gut barrier functions by modulating mucin production in the gut, which may eventually prevent gut mucosal inflammation (Graziani et al., 2016; Luissint et al., 2016). Using metatranscriptomics, Granata et al. (2020) showed that carbohydrate, amino acid, and nucleotide metabolism are severely impaired in the duodenal microbiota of obese patients compared to nonobese patients.

\subsubsection{Metaproteomics}

Metaproteomics employs high-resolution mass spectrometry to identify and measure the levels of expressed proteins (Mesuere et al., 2016). A microbial protein may have direct or indirect effects on other microbes and influence host physiology (Schweppe et al., 2015; Rolig et al., 2018), and identifying and quantifying gut microbial proteins (metaproteomics) provide a better picture of the role of gut microbes in health and disease. The information obtained is processed by pipelines that eventually match the peptides with metagenomic databases to determine the most likely microbes that might have expressed the proteins. The ability of metaproteomics to identify and quantify proteins from microbial and host sources makes it a powerful approach in studying microbial-host interactions (Gavin et al., 2018). Several platforms, such as MetaLab (Cheng et al., 2017), MetaQuantome (Easterly et al., 2019), Galaxy-P (Jagtap et al., 2015), and MetaProteomeAnalyzer (Muth et al., 2018), are available for processing metaproteomic data. Metaproteomics enables a clear identification of how disease conditions (or their triggers) result in gut microbial dysbiosis and which microbial protein may directly affect the 
host (Zhang X. et al., 2018; Long et al., 2020). For example, quantitative alterations in both host and microbial proteins due to intestinal inflammation can be highlighted via metaproteomics, and this approach can corroborate observed phylogenetic changes in bacteria (Mayers et al., 2017).

\subsubsection{Metametabolomics}

Metabolomics involves the study of metabolites in a biological sample as well as the exploration of microbe-derived therapeutic products. A targeted or untargeted approach can be used (Daliri et al., 2021). The former is used to study metabolites in specific pathways associated with a particular disease, while the latter measures as many metabolites in the sample as possible (Commisso et al., 2013; Vignoli et al., 2019). Analytical techniques include liquid chromatography, gas chromatography, mass spectrometry (MS), MS/MS, ultraviolet/ visible spectroscopy and nuclear magnetic resonance spectroscopy (Daliri et al., 2017). Metabolomics has been applied to detect biomarkers that can distinguish acute anterior uveitis (AAU) progression and treatment response (Guo et al., 2014). It allows determination of the metabolic pattern of the gut microbiota and discrimination between metabolites that may be associated with different disease courses (Peng et al., 2015; Huang et al., 2018; Vignoli et al., 2019). For example, hostbacterium cometabolites known to induce metabolic deteriorations in genetic and simple obesity in children determine specific bacterial genomes correlated with urine levels of these detrimental cometabolites (Heintz-Buschart et al., 2016).

Despite their costs and technical challenges, longitudinal and multiomic experimental designs are becoming indispensable for unravelling host-microbiome interactions during disease and for assessing causality in clinical microbiome investigations (Zhang et al., 2019). There are still some unsolved problems that interfere with the accuracy of the results, e.g., similar studies conducted by different groups of researchers sometimes yield varying results. The reason is that there is no standardization of sample preparation and analysis flow (Gorkiewicz et al., 2013; Xiong et al., 2015; Drago et al., 2016; Shobar et al., 2016; Nagata et al., 2019; Daliri et al., 2021). Importantly, a major challenge for metatranscriptomic sequencing is that it is difficult to eliminate rRNA contamination, as mRNAs only account for $5 \%$ of the total RNA in a cell (Liang et al., 2000; Jiang et al., 2016). Second, due to the limited richness of the comparison database, there are many measured results that are unable to match the function (Pasolli et al., 2019; Granata et al., 2020). Further work is needed to enrich the existing databases used for comparison.

Over the years, integrative multiomics analyses, referring to the combination of two or more omics analysis methods, have been proposed for studying host-microbiome interactions, which offer considerable information regarding microbial phylogeny and metabolic pathways and may provide clues for the specific proteins and metabolites that contribute to a specific host phenotype. (Daliri et al., 2021). Future investigations may consider combining several omic techniques rather than relying on only one or two techniques, which may be beneficial for compensating for the weakness of single-omic studies.

\subsubsection{Establishing a Well-Controlled Animal Experiment}

Environmental and dietary factors exert tremendous impacts on microbiota compositions, rendering it difficult to rigorously confirm the cause-and-effect relationship between microbiota and disease in clinical studies. Recently, several novel experimental models have been established to study the roles of microbiota in health and disease in living animals.

\subsubsection{Germ-Free Animals and Antibiotic Usage}

Removal of commensal microbiota by rearing animals in a germfree (GF) environment or by oral antibiotic treatment has been used to explore the link between the gut microbiota and ocular diseases, especially autoimmune diseases. GF mice have been widely used in studies of allergies (Vercelli, 2021), conjunctivitis (Wang et al., 2018; Zaidi et al., 2018), autoimmune uveitis (Horai et al., 2015), and diseases with ocular manifestations, such as Sjögren syndrome (SS) (Trujillo-Vargas et al., 2020). However, a concern of using GF mice is that the normal development of the immune system is strongly dependent on the microbiome, such that under GF conditions, the animal's response to immune stimuli may be blunted (Dzidic et al., 2018). Data from GF mouse studies must be interpreted in context, as several host physiologic parameters are altered in these mice. For example, GF mice have underdeveloped immune systems (Gaboriau-Routhiau et al., 2009; Ivanov et al., 2009; Atarashi et al., 2011), slower intestinal epithelial turnover (Savage et al., 1981), differences in epithelial gene expression (Chowdhury et al., 2007), and reduced body fat (Bäckhed et al., 2004).

The drawback of using broad-spectrum antibiotics is that there are unintended side effects on the host immune system. Compared with controls, mice treated with a cocktail of antibiotics have been observed to have weight loss and abnormal organs, such as reduced spleen size (Sun et al., 2021). This suggests that antibiotic usage leads to a duration of immune imbalance that must be considered in therapeutic strategies. Moreover, antibiotic cocktails do not completely exclude the direct or indirect effects of fungi or viruses on ocular disease.

Initially, a role for the gut microbiome in a phenotype of interest is determined by comparing antibiotic(ABX)-treated animals with untreated animals. If antibiotic treatment abrogates or exacerbates a model's phenotype, it may support some undefined role for the gut microbiome. The underlying assumption is that the antibiotic does not possess an effect on the model's phenotype itself. Thus, proper control groups, and often multiple different antibiotic regimens, are necessary to demonstrate a difference (Ericsson and Franklin, 2015). Another consideration is that even in the absence of overt changes in the compositions of the gut microbiome, antibiotics and other xenobiotics may significantly alter the transcriptional activity of the gut microbiome and impact the model's phenotype (Maurice et al., 2013). The removal of even a small portion of commensal microbes by antibiotics might disrupt microbial syntrophy, which may not lead directly to phenotypic changes but may lead to subsequent changes in larger microbial populations, resulting in changed phenotypes. Thus, any 
alterations in phenotype by antibiotic treatment must be interpreted cautiously to separate the effects of the gut microbiome from the antibiotics themselves (Ericsson and Franklin, 2015).

\subsubsection{Methods of Humanized Gnotobiotic Models}

To better simulate the human environment, the human microbiota has been applied to GF or ABX animals (Turnbaugh et al., 2009; Walter et al., 2020). Targeting fecal transplants at the strain level, a single causative organism may be identified to discuss causality more accurately. In the past decade, gnotobiotic human microbiota-associated (HMA) mice have been widely used to study causality and mechanisms of microbiome-disease associations, such as the contribution of a dysbiotic microbiome to a particular pathology (Walter et al., 2020). Compared to mice colonized with the microbiota from healthy controls, GF mice are usually colonized with the fecal microbiota from patients. A seminal study showed that GF transgenic mice expressing a myelin autoantigen-specific TCR reconstituted with fecal samples from MS patients developed more serious clinical scores on spontaneous EAE than healthy stool-recipient gnotobiotic mice (Berer et al., 2017).

While being an ideal model for studying the effects of the microbiome, there are some limitations of HMA mouse models that might affect data interpretations: (1) evolutionary considerations: under the pressure of long-term coevolution, the dynamic host-microbiota interactions might shift to a more host-beneficial and host-specific form; (2) ecological considerations: some species that abundantly exist in the human gut microbiome might fail to efficiently colonize the mouse gut or expand in a fashion that does not mimic their physiological states in the human gut but rather establishes a microbiome signature resembling that of recipient mice (Arrieta et al., 2016). This is because recipient mice are subjected to different ecological factors and immune environments than human donors. Ecological factors such as diet, human behavior, human genotype, and human immunity that help shape the microbial signature in humans are no longer present or may manifest differently in recipient mice (Arrieta et al., 2016). The data generated using HMA mouse models, therefore, may not be able to be used to accurately interpret the pathophysiological relevance of microbial imbalance in humans. Better simulation models must be developed.

\section{ROLE OF MICROBIOTA IN OCULAR DISEASE}

\subsection{Autoimmune Uveitis}

Autoimmune uveitis is a heterogeneous collection of diseases characterized by intraocular inflammation and a major cause of blindness in humans (Jabs et al., 2005; Forrester et al., 2013). Both genetic and environmental factors impact the development of autoimmune uveitis (Kamada et al., 2013). Based on current perspectives, its pathogenesis may be attributable to the abnormal activation of Th cells, specifically the imbalance between inflammatory Th1/Th17 and Treg cells (Eisenstein and Williams, 2009; Lee et al., 2014; Noack and Miossec, 2014). It is hypothesized that the activation of intraocular inflammation requires activated retinal antigen-specific lymphocytes to breach the blood-retinal barrier and migrate into the retina (Caspi, 2010). This raises an intriguing question of how the retinal antigens that are sequestered in the eye trigger $\mathrm{T}$ cell activation in peripheral circulating blood. Recently, emerging evidence has shown that gut microbiota may play an essential role in the development of uveitis.

Clinically, dysbiosis in gut bacterial communities has been observed in uveitis patients (Kalyana Chakravarthy et al., 2018). Transfer of the gut microbiome from patients with $\mathrm{BD}$ and VKHD, both of which are characterized by multiorgan inflammation involving uveitis, has been shown to significantly exacerbate disease severity in recipient experimental autoimmune uveitis (EAU) mice (Ye et al., 2018; Ye et al., 2020). The classic EAU animal model is induced by active immunization with the retinal protein interphotoreceptor retinoid-binding protein (IRBP) emulsified in complete Freund's adjuvant (CFA) with heat-killed Mycobacterium tuberculosis (MTB), and severe ocular inflammation is observed within 2 weeks after induction (Weinstein and Pepple, 2018). Oral antibiotics substantially attenuate ocular inflammation in EAU mice (Nakamura et al., 2016). Notably, antibiotics applied through the intraperitoneal route have limited effects on eliminating commensals and do not alter disease progression in EAU, suggesting that the amelioration of EAU by antibiotic treatment is not due to the anti-inflammatory effects of antibiotics themselves (Nakamura et al., 2016). In another study, combining remodeling of the gut microbiome with immunosuppressive therapy significantly hindered the progression of EAU after inflammation onset (Zhou et al., 2020). The microbiome of EAU mice is distinct from that of controls (Horai and Caspi, 2019), which could be a result of robust immune activation by CFA.

To rule out the influence of CFA, spontaneous uveitis models have been introduced. These models were initially used to study how peripheral $\mathrm{T}$ cells enter the eye and later were used to study how endogenous antigens activate immune cells. The pathogenic mechanisms of spontaneous and immunized models are different because uveitis in spontaneous models is likely triggered by endogenous antigens (Horai and Caspi, 2019). R161H mice overexpress IRBP-specific TCRs on uveitis-susceptible B10 cells. The RIII background has been shown to expand the peripheral population of uveitis-relevant $\mathrm{CD}^{+} \mathrm{T}$ cells that appear in the intestinal lamina propria (LP) as early as 17 days of age, and uveitis has been shown to have $100 \%$ penetrance in these mice by 2 months of age (Horai et al., 2013). In one study, the degree of intraocular inflammation was significantly attenuated accompanied by reduced populations of Th17 cells in the intestinal LP when the mice were given a cocktail of oral broad-spectrum antibiotics before birth or were reared under GF conditions, and disease development was restored after cohousing with specific pathogen-free (SPF) mice (Horai et al., 2015). Interestingly, in contrast, the microbiota seem to be 
dispensable in another spontaneous model, i.e., in Aire-deficient $\left(\right.$ A $^{-} \mathrm{I}^{-}$) mice. The Aire protein has a critical role in the process of thymic negative selection of autoreactive T cells and prevents autoimmunity by promoting the deletion of potentially selfreactive thymocytes (Anderson et al., 2002; Anderson et al., 2005; Proekt et al., 2017). Similar inflammatory infiltration occurs in several tissues in SPF and GF Aire ${ }^{-}{ }^{-}$mice, including the retina, lung, pancreas, and stomach (Gray et al., 2007). The same finding has been reported in Aire ${ }^{\mathrm{GW} /+} \mathrm{Lyn}^{-1-}$ doublemutant mice with spontaneous posterior uveitis in which broad-spectrum antibiotics had no effects in treating the disease (Proekt et al., 2016). Thus, eliminating the influence of the microbiota alone cannot completely exclude other unknown mimics that may be able to activate high-affinity retina-specific $\mathrm{T}$ cells in the thymus of Aire / or Aire ${ }^{\mathrm{GW} /+} \mathrm{Lyn}^{-/-}$mice. Further investigations are needed to delineate these seemingly contradictory results.

In a study of $\mathrm{R} 161 \mathrm{H} \mathrm{IRBP}^{-/-}$mice, they displayed no uveitis but had a similar high frequency of Th17 cells in the gut compared with that in IRBP-sufficient $\mathrm{R} 161 \mathrm{H}$ mice (Horai et al., 2015). Furthermore, R161H T cells cocultured with bacteria-rich intestinal contents in vitro can be turned into uveitis-pathogenic $\mathrm{T}$ cells, while this transformation was destroyed when intestinal contents were inactivated or were isolated from GF mice (Horai et al., 2015). These observations implied that IRBP is not the only antigen for uveitis and that microbiota stimuli can work as antigen mimics to activate $\mathrm{T}$ cells. Moreover, some studies have indicated that microbe metabolites can also affect uveitis. Propionate, one of the SCFAs produced by gut bacteria, has been confirmed to increase Tregs in the intestinal LP at the early stage of EAU in C57BL/6 mice, promoting barrier functions and maintaining the structural stability of the intestine (Smith et al., 2013; Nakamura et al., 2017; Sun et al., 2017). Thus, it has been proposed that intestinal commensal microbes, as antigenic mimics, alter the immune system, allow peripheral $\mathrm{T}$ cells to breach the blood retinal barrier, and cause inflammation in the eye.

In humans, anterior uveitis accounts for $85 \%$ of all instances of uveitis, representing the most common type (Gritz and Wong, 2004). Approximately $50 \%$ of patients with AAU are human leukocyte antigen B27 (HLA B27)-positive (Rosenbaum, 1989). HLA genes, such as major histocompatibility complex (MHC) genes, are the most polymorphic genes known (Jin and Wang, 2003). They are important mediators of the immune recognition of foreign pathogens by cytotoxic $\mathrm{T}$ cells and are therefore crucial in defense against foreign pathogens (Rosenbaum and Asquith, 2018). HLA B27 has been studied extensively for detecting the association between ankylosing spondylitis (AS) and spondyloarthropathies (SpA) (Khan, 2008). Recently, a well-defined clinical phenotype for SpA patients with AAU complications has been reported (Yang et al., 2018). However, HLA B27 transgenic animals develop a disease that strongly resembles human SpA but not AAU (Baggia et al., 1997). Interestingly, GF HLA-B27 rats do not display inflammation in the gut and joint, suggesting that commensals are probably involved to some extent in HLA B27-associated inflammation (Taurog et al., 1994).
To date, there are only limited investigations devoted to the immunopathogenesis of HLA B27-positive AAU. Testing fecal samples of AAU patients and healthy humans revealed no difference in gut microbiota composition; however, there was a clear difference in the fecal metabolic phenotypes (Huang et al., 2018). The absence of differences in microbiota may be due to a lack of sufficient patient samples. In some other HLA-associated diseases, the genotypes seem to affect the gut microbiome compositions. The HLA-DQ2 genotype that predisposes infants to celiac disease alters the gut microbiome, as demonstrated in a study of infants (Olivares et al., 2015). Further studies of the relationship between microorganisms and HLA may help us speculate on the pathogenesis of HLAassociated AAU. It has been shown that a large number of microbial peptides bind the HLA B27 molecule, and such microbial peptides may induce immune responses in target organs such as the eye and joint (Bodis et al., 2018). Chlamydia-derived peptides have been identified to immunize rats with occasional uveitis (Wakefield et al., 1991). Patients with AS have been described as having increased gut permeability (Colmegna et al., 2004). Additionally, endotoxin, which is a component of the gram-negative bacterial cell wall, has been used to induce anterior uveitis in experimental animal models (Hoekzema et al., 1992). In line with this evidence, the expression of Toll-like receptor 4 , which binds endotoxin, has been found to be upregulated in the peripheral blood of AAU patients (Chang et al., 2007). One of the earliest immunological changes in HLA B27 transgenic rats with SpA is an upregulation of antimicrobial peptides such as S100A8 (calprotectin) in the colon (Asquith et al., 2016), which has been reported to be a biomarker for posterior uveitis (Olson et al., 1996). Notably, these changes may precede the development of dysbiosis in these animals (Rosenbaum and Asquith, 2018). These findings provide strong evidence for gut microbes or their metabolites as a trigger for altering the permeability of the gut wall and even entering the regional lymph nodes to generate a systemic immune response.

\subsection{Age-Related Macular Degeneration}

Age-related macular degeneration is a degenerative disorder that leads to impaired central vision, preferentially affecting the macular region of the retina (Chew et al., 2015). It is a polygenic disease that can be classified into dry and wet forms, both of which are influenced by environmental factors. These factors include disruptions in lipid, carotenoid, and inflammatory pathways induced by diet, smoking, and certain gene variants (Korobelnik et al., 2015; Chapman et al., 2019). Dry AMD causes damage to the retinal pigment epithelium (RPE), leading to indirect photoreceptor cell damage, while wet AMD is usually observed with choroidal neovascularization (CNV), which leads to RPE detachment and ultimately RPE cell death (Tadayoni, 2014).

A study reported that intestinal dysbiosis might occur in individuals with advanced AMD who had different types of gut bacteria compared to those in healthy older adults, such as the bacterial genera Anaerotruncus and Oscillibacter and the species 
Ruminococcus torques and Eubacterium ventriosum (Zinkernagel et al., 2017). However, the abundance of Oscillospira, Blautia, and Dorea was reduced in AMD subjects compared with healthy controls (Lin, 2018; Lin, 2019). Using high-throughput RNA sequencing in GF mice, Skondra and colleagues revealed key aspects of retinal gene regulation in AMD that are modulated by the intestinal microbiota (Nadeem et al., 2020). Although the exact pathogenesis of AMD remains poorly understood, certain inflammatory mechanisms associated with innate immunity have been identified. There are currently two hypotheses about microbial disorders influencing the progression of AMD, including immune regulation and promotion of nutrient absorption.

Regulated immune activation via recruitment of microglia and macrophages into the subretinal and choroidal areas, mast cell activation, and RPE immune activation presumably play a role in AMD pathogenesis (Handa et al., 2019). The gut microbiome may influence inflammation and the function of microglia during AMD progression. A study demonstrated that compared to normal-diet-fed mice, mice fed a high-fat diet were associated with intestinal dysbiosis and had a twofold increase in the number of microglia and macrophages within the local CNV lesions and that this increase was mitigated by eradicating the gut microbiota via neomycin application (Andriessen et al., 2016). Feeding aged mice heat-killed Lactobacillus paracasei, a lactic acid-producing bacterium, activated macrophages but paradoxically suppressed inflammation, resulting in a reversal of the deleterious Firmicutes/Bacteroidetes ratio and a decrease in both age-related inflammation and ganglion cell loss in the retina (Morita et al., 2018).

Oral supplements, antioxidants, minerals, and a diet containing carotenoids have been found in the Age-Related Eye Disease Studies (AREDS and AREDS2) to reduce the risk of AMD progression (Chew et al., 2015). Oral antioxidant supplementation according to AREDS2 is the only intervention that appears to slow the progression of AMD (Napolitano et al., 2021). Recent studies have shown that their efficacy is mediated by intestinal microbiota. For example, in a murine model of choroidal neovascularization, feeding mice a high-fat diet after administration of oral antibiotics can reduce CNV growth and improve alterations in the composition of the microbiome (Andriessen et al., 2016). Similar alterations in the intestinal microbiota have been shown to occur in mice with AMD-like characteristics fed a high-sugar diet, a high-fat diet or long-chain fatty acids (Zhang M. et al., 2018; Baim et al., 2019). On the other hand, a low-sugar diet did not impact the retina or the intestinal microbiota in this manner (Rowan et al., 2017). Although different lines of evidence indicate an association between AMD and diet-induced changes in gut microbiota, it is still unclear whether a causal relation truly does exist.

\subsection{Glaucoma}

Glaucoma is an incurable neurodegenerative disorder and the second leading cause of blindness worldwide; it is characterized by the death or dysfunction of retinal ganglion cells (RGCs), the axons of which lose intrinsic capacity to regenerate (Quigley and Broman, 2006; Lobato, 2008; Baden et al., 2016). Common therapeutic strategies to support visual restoration include protecting RGCs from degeneration, promoting regeneration of RGCs and axons after injury, and reestablishing the correct projection relationship (Hasegawa et al., 2004; Danesh-Meyer, 2011; Lusthaus and Goldberg, 2019; Schuster et al., 2020). Elevated intraocular pressure (IOP) is the most prominent threatened factor, while the inflammatory signals caused by injury recruit cellular and molecular processes and have been shown to affect the inherent regeneration ability (Yuan et al., 2021). Given the involvement of $\mathrm{CD}^{+} \mathrm{T}$ cells as well as the microbiota in the pathogenesis of glaucoma, it has been recently suggested that glaucoma should be included in the spectrum of autoimmune diseases (Geyer and Levo, 2020). An interesting study conducted by Chen et al. (2018) reported that a transient increase in IOP can induce autoreactive $\mathrm{T}$ cells to infiltrate the retina and that these $\mathrm{T}$ cells are presensitized by the symbiotic microbiota. Recently, commensal microbiota dysbiosis, including gut and oral microbiota dysbiosis, has been recognized to play a crucial role in the onset of neurological disorders and progressive neuronal loss (Schloss and Handelsman, 2004). DBA/2J mice are frequently used as a murine model for glaucoma because they spontaneously develop high IOP, mild intraocular inflammation, and glaucoma by 6-8 months of age (Libby et al., 2005). Interestingly, GF DBA/ 2J mice do not show typical axonal degeneration or neuronal loss at 12 months of age (Chen et al., 2018).

In the past two decades, the relationship between Helicobacter pylori infection and the pathogenesis of open-angle glaucoma (OAG) has become an active area of research. The connection between them was first proposed by Dr. Kountouras et al. (2001). Further study revealed that $H$. pylori might be a trigger of the systemic autoimmune response, which leads to the release of numerous inflammatory substances (Chmiela and Michetti, 2006). Mechanistically, H. pylori might influence the trabecular meshwork cell apoptotic process and crossreact with ciliary body epithelial antigens (Galloway et al., 2003; Burucoa and Axon, 2017). However, whether H. pylori plays a role in early onset is still a question (Deshpande et al., 2008; Kurtz et al., 2008). A meta-analysis combining all the relative results was conducted in 2015 (Zeng et al., 2015). The summary odds ratio (OR) and 95\% confidence interval (CI) were calculated using the random-effects model. The results of this meta-analysis suggested a statistically significant association between $H$. pylori infection and primary open-angle glaucoma (POAG) or normal tension glaucoma (Zeng et al., 2015).

The potential correlation between the gut microbiota and glaucoma has been shown in several studies. POAG patients and healthy people have distinct profiles of gut microbiome compositions and serum metabolites (Gong et al., 2020). Butyrate, a gut bacterial metabolite, has been shown to lower IOP independently of blood pressure changes in rats (Skrzypecki et al., 2018). In addition, an increased level of trimethylamine, a uremic toxin produced by gut microbiota, has been observed in the aqueous humor of patients with glaucoma (Skrzypecki et al., 2021).

Heat shock proteins (HSPs) are highly conserved from bacteria to humans. Chen et al. (2018) demonstrated that glaucomatous mice induced by IOP may harbor HSP-specific 
memory $\mathrm{T}$ cells that were originally induced by commensal bacteria (Flemming, 2018). HSP27 and HSP60 have been found to be upregulated on RGCs in human glaucoma, and higher levels of serum HSP27-specific antibodies have been found in an experimental model (Chen et al., 2018). Low-dose subcutaneous lipopolysaccharide (LPS) administered to two animal models of glaucoma resulted in upregulation of TLR4 signaling and complement and activation of microglia in the retina and optic nerve (Astafurov et al., 2014). Enhanced oral bacterial loads have been shown to be correlated with a higher chance of glaucoma (Astafurov et al., 2014). Taken together, these results suggest that gut bacteria-triggered $\mathrm{CD} 4^{+} \mathrm{T}$ cells play a role in the induction of glaucoma by entering the eyes after the blood-retina barrier is damaged by pressure and causing neurodegeneration through crossreaction with HSP-expressing RGCs (Flemming, 2018). The exact role of gut microbiota in the development and progression of glaucoma remains to be explored.

\subsection{Ocular Surface Microbiome Dysbiosis and Ocular Diseases}

As the ocular surface is subjected to constant washing by tears and other antimicrobial ocular secretions, the presence of commensal bacteria at the ocular surface has been debated. However, cultural and sequencing evidence from ocular surface swabs clearly demonstrate the habitats of microbes on the ocular surface (Wu et al., 2003; Miller and Iovieno, 2009; Zhou et al., 2014; Huang et al., 2016). The ocular microbiota can be influenced by environmental conditions, disease states, use of antibiotics, age, sex, personal habits, contact lens wear, etc. (Stapleton et al., 2007; Lu and Liu, 2016; Ozkan et al., 2017; Wen et al., 2017; Cavuoto et al., 2018). Recently, persistent colonization of $E$. faecalis was identified on the ocular of patients with chronic ocular surface diseases (Todokoro et al., 2018). Alterations of the normal ocular microbial flora are related to several disease states, such as blepharitis, conjunctivitis, keratitis, trachoma, and dry eye syndrome (Schabereiter-Gurtner et al., 2001; Graham et al., 2007; Lee et al., 2012; Kugadas et al., 2016).

Microbial keratitis is an infectious ocular disease in which the cornea is inflamed. Under severe conditions, keratitis can lead to significant loss of vision and enucleation of the eye (Cruz et al., 1998). Pseudomonas aeruginosa (P. aeruginosa) is one of the gram-negative bacteria most frequently isolated from patients with bacterial keratitis (Al-Mujaini et al., 2009). The contribution of the ocular surface microbiome to the induction of keratitis by infectious $P$. aeruginosa has been documented (Kugadas et al., 2017). Wearing contact lenses is a possible risk factor for the development of microbial keratitis and other inflammatory eye conditions (Eguchi et al., 2017b; Miyazaki et al., 2020).

Bacilli are most prominent in patients with dry eye disease (Zilliox et al., 2020; Andersson et al., 2021). Meibomian gland dysfunction often leads to evaporative dry eye syndrome. The severity of MGD has been shown to be positively correlated with a higher isolation rate, a greater number of bacterial species, and a higher grade of bacterial severity (Jiang et al., 2018). Staphylococcus, Corynebacterium, and
Sphingomonas may be involved in the pathophysiology of MGD (Pinna et al., 2005; Dong et al., 2019). Moreover, SS is a chronic autoimmune disease associated with dry mucosal surfaces and other systemic muscular pain (Both et al., 2017; Kuklinski and Asbell, 2017). SS-related dry eye patients share similar gut dysbiosis features (Kuklinski and Asbell, 2017). Several gut bacterial species are associated with the severity of dry eye parameters (de Paiva et al., 2016; Mendez et al., 2020; Moon et al., 2020).

Trachoma, caused by Chlamydia trachomatis, remains the leading infectious cause of blindness worldwide. A decrease in diversity and an increase in the abundance of Corynebacterium and Streptococcus were seen in participants with conjunctival scarring compared to normal controls. Importantly, Chlamydia trachomatis infections have been associated with reduced bacterial diversity and with an increase in the Corynebacterium and Streptococcus genera (Zhou et al., 2014). Pickering et al. reasoned that the potential mechanism may be associated with altered innate immune responses to the microbiota, dominated by altered mucin expression and increased matrix adhesion (Pickering et al., 2019). Moreover, Corynebacterium mastitis firmly colonized the conjunctiva increased its resistance to pathogens and stimulated the production of interleukin-17 by conjunctival $\mathrm{T}$ cells, allowing the recruitment of a greater number of neutrophils (St Leger et al., 2017).

Some studies have also reported the contribution of microorganisms to the development of ocular neoplasms. Examples include human papillomavirus, the cause of human conjunctival papilloma, which has been associated with squamous cell carcinoma, and HIV viruses, which have been associated with conjunctival squamous cell carcinoma (Miller and Iovieno, 2009).

\subsection{Gut-Eye Axis}

A dogma in ophthalmic research is that the intraocular environment is always sterile under physiological conditions. Nevertheless, emerging evidence, including the translocation of intestinal bacteria into the circulating blood (Kell et al., 2015), liver (Vieira et al., 2018), pancreas (Aykut et al., 2019) and many other organs, argues against intraocular sterility. As the first and foremost finding, our group identified the presence of an intraocular microbiota via quantitative PCR, negative staining transmission electron microscopy, direct culture, and highthroughput sequencing technologies. We also analyzed aqueous humor samples collected from four species, i.e., rat, rabbit, pig, and macaque, and confirmed the existence of an intraocular microbiota (Deng et al., 2021). These observations raise an intriguing question of how microbes enter the eye (Figure 1). One speculation is that intraocular microbes originate from the gut, where they breach into circulating blood when a certain disease circumstance causes damage to the mucosal barriers and increases intestinal permeability. Both gut microbiota and their metabolites might be endogenous culprits of ocular diseases, possibly exerting their function by molecular mimicry and integrated immunological pathways. There is evidence that certain bacteria can survive in autophagosomes within phagocytes, à la a Trojan horse, and 


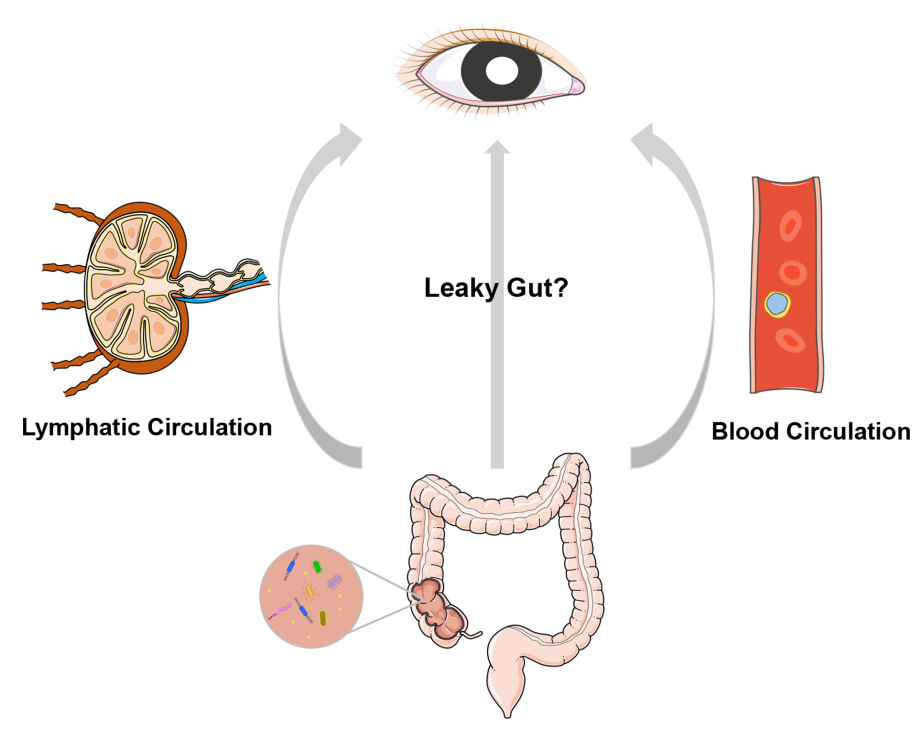

FIGURE 1 | A cartoon illustration of the "gut-eye axis". Dysbiosis of the intestinal microbiota of disruption in the intestinal barrier may result in translocation of the intestinal bacteria and/or their metabolites into circulatory system and lymphatic system, and further impact the eye, which is remotely located from gut.

migrate with these cells through barriers from the gut to other body sites (Berthelot et al., 2015; O'Keeffe et al., 2015).

The immune response triggered by antigenic mimicry is the process whereby autoreactive $\mathrm{T}$ cells are generated through cross reactivity with gut microbial peptides as self-antigens (Rojas et al., 2018). In line with this theory, a study found that several peptides derived from commensal bacteria activated Ro60reactive $\mathrm{T}$ cell hybridomas (Szymula et al., 2014). Ro60/SSA is one of the major autoantigens in SS and systemic lupus erythematosus. Repeated injections of the outer membrane protein A of E. coli induced the production of SS-related autoantibodies (Yanagisawa et al., 2018). Microbial cross reactivity has also been demonstrated in patients with systemic lupus erythematosus. One of these identified commensals, Propionibacterium propionicum, activated Ro60-specific memory CD4 T cells isolated from lupus patients (Greiling et al., 2018). Similarly, gut commensal bacteria have been shown to share homologous autoantigens in rheumatoid arthritis patients (Pianta et al., 2017).

Disruption in the intestinal barrier may result in leakage of bacteria or their metabolites into the blood or lymphatic system, irritating local or systemic immune responses. One such example is that SCFAs have been shown to increase colonic Treg frequencies in the gut in mice (Smith et al., 2013). In an EAU model, intestinal dysbiosis accompanies a disruption in intestinal integrity (Janowitz et al., 2019). In addition, oral administration of SCFAs can alleviate the development of EAU (Nakamura et al., 2017). The mechanism currently speculated is that bacterial products and pathogen-associated molecular patterns (PAMPS) enter the circulation and interact with downstream pattern recognition receptors (PRRs). The interaction between microbiota and Toll-like receptors (TLRs) activates the innate immune response. In cancer research, tumor-type-specific intracellular bacteria have been detected in multiple human tumors, although at low biomass (Nejman et al., 2020; Poore et al., 2020). These microbes are believed to play roles in tumorigenesis. Considerable evidence demonstrates the roles of microbes in Alzheimer's disease, Parkinson's disease, and autism, corroborating the theory of the gut microbiota-brain axis (Caputi and Giron, 2018; Angelucci et al., 2019; Morais et al., 2021). Likewise, maintaining homeostasis of the gut microbiota-eye axis might be a feasible strategy for the therapy of ophthalmic diseases.

\section{MICROBIAL THERAPEUTICS}

Ophthalmic antibiotics have been used to treat and prevent a variety of infectious and inflammatory conditions. The shift in the ocular microbiome influences ocular homeostasis and may increase the risk of eye infection (Miller and Iovieno, 2009; Mshangila et al., 2013). The administration of antibiotics causes ocular microbiota alteration, and extensive usage may promote the development of antibiotic resistance. Fecal microbiota transplantation (FMT), which involves placing stool from a normal donor into the gastrointestinal tract of a patient, has been controversial due to its safety and transient effect (Rosenbaum and Asquith, 2018). In addition, the challenge is the complexity of the diet-regulated gut microbiome, which makes it very difficult to identify the components that need to be added or subtracted for sustained benefit (Rosenbaum and Asquith, 2018). Probiotic and relative metabolite regimens and bacteriophage therapy have been proposed in recent years as surrogates for antibiotic treatment. 


\subsection{Probiotics and Relative Metabolites}

Probiotic regimens have become a popular dietary intervention taking advantage of their transient and noninvasive properties, which help maintain a healthy immune system by improving gut health. Probiotics are thought to modulate immune responses, protect against physiological stress, suppress invasion of pathogens, modulate microbiota, and improve the barrier function of the gut epithelium (Shakya et al., 2019). Lactobacilli, for example, is able to decrease the number of neutrophil extracellular traps (Klenkler and Sheardown, 2004). Bacillus fragilis provides protective effects against autoimmune disease through its polysaccharide capsule (Knop and Knop, 2007). Some ongoing studies are evaluating the stability of an eye drop probiotic formulation containing Saccharomyces boulardii and Lactobacillus rhamnosus in patients with vernal keratoconjunctivitis. Bifidobacterium promotes the isolation and utilization of SCFAs, which have been identified to have a direct effect on modulating gut mucosal immunity and decreasing the severity of EAU (Knop and Knop, 2007; Rivière et al., 2016). The combination of probiotics including lactobacillus gasseri KS-13, Bifidobacterium bifidum G9-1, and B. longum MM-2 improved rhinoconjunctivitis during allergy through increasing serum total IgE and the percentage of Tregs from baseline (Dennis-Wall et al., 2017). Chisari et al. proved that the administration of Enterococcus faecium and Saccharomyces boulardii on the tear film was effective in ameliorating dry eye syndrome (Chisari et al., 2017) Changes in the gut microbiome after IRT5 treatment, a mixture of five probiotic strains, have been shown to improve clinical manifestations in the autoimmune dry eye model via the downregulation of antigen-presenting processes in immune networks (Choi et al., 2020). Meanwhile, IRT5 probiotics can modulate EAU by decreasing the percentage of pathogenic CD8+ $\mathrm{T}$ cells in drainage lymph nodes (Kim et al., 2017). Interestingly, Lactobacillus paracasei KW3110 improved the function of cultured RPE cells under chronic inflammatory stress and could relieve eye fatigue in humans safely (Yamazaki et al., 2020).

The selective metabolization of prebiotics in the gut by host microorganisms can purportedly determine the growth and functionality of local bacteria that influence human health (Napolitano et al., 2021). How probiotics modulate the intestinal microbial balance is poorly understood, and the molecular mechanisms have yet to be studied.

\subsection{Bacteriophage Therapy}

Some diseases have been shown to be associated with specific microbiota markers in recent studies. The precise modulation of microbiota via phage therapy shows potential for treating microbiota-associated diseases. Compared with traditional antibiotic therapy, phages display extremely high selectivity to target bacteria and good biosafety in humans. Phage-mediated modulation of microbiota has been shown to eliminate drugresistant infections and improve conventional antitumor strategies (Zhang et al., 2021). Furthermore, it is a more efficient method because of its destructiveness to host bacteria and high fertility (Weinbauer, 2004).
Santos et al. reported that the isolated bacteriophages P2S2 and P5U5 were potential candidates for phage treatment of infection of ulcerative keratitis caused by $P$. aeruginosa in dogs (Santos et al., 2011). The therapeutic potential of Ply187ANKSH3b, a chimeric phage endolysin derived from the Ply187 prophage, has been evaluated in treating bacterial endophthalmitis with promising results (Singh et al., 2014). Wang et al. (2016) used 4 phages selected from sewage to selectively kill cytolytic Enterococcus faecalis to treat ethanolinduced liver injury and steatosis in GF mice that were transplanted with the fecal microbiota of cytolysin-positive patients. A later study found that combining silver nanoparticles with M13 phage could specifically eliminate Fusobacterium nucleatum in the gut and reduce the number of immunosuppressive myeloid-derived suppressor cells, which improved the efficacy of checkpoint inhibitor-mediated immunotherapy for colorectal cancer (Dong et al., 2020). An advantage of using phages is that their effects on the microbiome are holistic, not limited to merely the removal of sensitive bacteria, and are cascadic on other bacterial species via the interaction between different bacteria (Wang et al., 2016; Hsu et al., 2019). Filamentous phages and T4 phage have been shown to have immunosuppressive effects in EAE or murine collageninduced arthritis models (Rakover et al., 2010; Międzybrodzki et al., 2017). Recently, it was reported that after subconjunctival injection of the thermodynamically and chemically stable RNA nanoparticles derived from the three-way junction of the pRNA from bacteriophage phi29 DNA packaging motor, up to $70 \%$ of the retinal cells contained the nanoparticles at $24 \mathrm{~h}$ after the injection (Shi et al., 2018). This may provide a new way for intraocular drug delivery. Although the host microbiota has been proven to be involved in the occurrence and development of many diseases, most mechanisms of action between the microbiota and host are still not clear. The correlations between phages, microbiota, and hosts need to be further confirmed in the future (Zhang et al., 2021).

\section{CONCLUSION}

The gut microbiota is so important that it dictates normal development and homeostasis in mammals, which may subsequently affect ocular health. Although a growing amount of evidence suggests that ocular disease progression is associated with altered gut microbial composition, the direct interconnections between gut microbiota and eye function require a solid molecular mechanistic foundation. We have recently identified an intraocular microbiota in normal living animals and in patients with ocular diseases (Deng et al., 2021). These observations raise several interesting questions: How did the microbes enter the eye and affect the ocular diseases? Did they originate from the gut microbiota and travel through the peripheral circulating blood? How do intestinal and intraocular microbiota crosstalk with each other? Microbes has been recently reported to present in normal human circulating blood (Damgaard et al., 2015; Potgieter et al., 2015; Paisse et al., 2016; Schierwagen et al., 2019). One hypothesis 
is that temporary breach of blood-retina barrier gives the bloodstream microbes which presumably emanate from the gastrointestinal tract a chance to enter the eye. Migration of microorganisms into the eye may be mediated by phagocytes under the immune imbalance caused by ocular diseases. Detailed mechanisms relating to the potential immunological links between microbes-derived antigens and ocular tissues has been discussed in detailed in another review (Li et al., 2020). The process likely involves TLRs, resident ocular antigen-presenting cells, such as ocular dendritic cells, MHCs and miscellaneous inflammatory mediators. The interrelationship between microbiota and homeostatic immunity of whole body (such as abundance commensals of oral, lungs and skin) as well as of local ocular

\section{REFERENCES}

Abu-Ali, G. S., Mehta, R. S., Lloyd-Price, J., Mallick, H., Branck, T., Ivey, K. L., et al. (2018). Metatranscriptome of Human Faecal Microbial Communities in a Cohort of Adult Men. Nat. Microbiol. 3, 356-366. doi: 10.1038/s41564-017-0084-4

Almeida, A., Mitchell, A. L., Boland, M., Forster, S. C., Gloor, G. B., Tarkowska, A., et al. (2019). A New Genomic Blueprint of the Human Gut Microbiota. Nature 568, 499-504. doi: 10.1038/s41586-019-0965-1

Al-Mujaini, A., Al-Kharusi, N., Thakral, A., and Wali, U. K. (2009). Bacterial Keratitis: Perspective on Epidemiology, Clinico-Pathogenesis, Diagnosis and Treatment. Sultan Qaboos Univ. Med. J. 9, 184-195.

Anderson, M. S., Venanzi, E. S., Chen, Z., Berzins, S. P., Benoist, C., and Mathis, D. (2005). The Cellular Mechanism of AIRE Control of T Cell Tolerance. Immunity 23, 227-239. doi: 10.1016/j.immuni.2005.07.005

Anderson, M. S., Venanzi, E. S., Klein, L., Chen, Z., Berzins, S. P., Turley, S. J., et al. (2002). Projection of an Immunological Self Shadow Within the Thymus by the Aire Protein. Science 298, 1395-1401. doi: 10.1126/science.1075958

Andersson, J., Vogt, J. K., Dalgaard, M. D., Pedersen, O., Holmgaard, K., and Heegaard, S. (2021). Ocular Surface Microbiota in Patients With Aqueous Tear-Deficient Dry Eye. Ocul. Surf. 19, 210-217. doi: 10.1016/j.jtos.2020.09.003 Andriessen, E. M., Wilson, A. M., Mawambo, G., Dejda, A., Miloudi, K., Sennlaub, F., et al. (2016). Gut Microbiota Influences Pathological Angiogenesis in Obesity-Driven Choroidal Neovascularization. EMBO Mol. Med. 8, 13661379. doi: 10.15252/emmm.201606531

Angelucci, F., Cechova, K., Amlerova, J., and Hort, J. (2019). Antibiotics, Gut Microbiota, and Alzheimer's Disease. J. Neuroinflamm. 16, 108. doi: 10.1186/ s12974-019-1494-4

Aron-Wisnewsky, J., and Clément, K. (2016). The Gut Microbiome, Diet, and Links to Cardiometabolic and Chronic Disorders. Nat. Rev. Nephrol. 12, 169181. doi: 10.1038/nrneph.2015.191

Arrieta, M. C., Walter, J., and Finlay, B. B. (2016). Human Microbiota-Associated Mice: A Model With Challenges. Cell Host Microbe 19, 575-578. doi: 10.1016/ j.chom.2016.04.014

Asquith, M. J., Stauffer, P., Davin, S., Mitchell, C., Lin, P., and Rosenbaum, J. T. (2016). Perturbed Mucosal Immunity and Dysbiosis Accompany Clinical Disease in a Rat Model of Spondyloarthritis. Arthritis. Rheumatol. 68, 21512162. doi: 10.1002/art.39681

Astafurov, K., Elhawy, E., Ren, L., Dong, C. Q., Igboin, C., Hyman, L., et al. (2014). Oral Microbiome Link to Neurodegeneration in Glaucoma. PLoS One 9, e104416. doi: 10.1371/journal.pone.0104416

Atarashi, K., Tanoue, T., Shima, T., Imaoka, A., Kuwahara, T., Momose, Y., et al. (2011). Induction of Colonic Regulatory T Cells by Indigenous Clostridium Species. Science 331, 337-341. doi: 10.1126/science.1198469

Aykut, B., Pushalkar, S., Chen, R., Li, Q., Abengozar, R., Kim, J. I., et al. (2019). The Fungal Mycobiome Promotes Pancreatic Oncogenesis via Activation of MBL. Nature 574, 264-267. doi: 10.1038/s41586-019-1608-2

Bäckhed, F., Ding, H., Wang, T., Hooper, L. V., Koh, G. Y., Nagy, A., et al. (2004). The Gut Microbiota as an Environmental Factor That Regulates Fat Storage. Proc. Natl. Acad. Sci. U. S. A. 101, 15718-15723. doi: 10.1073/pnas.0407076101 tissues warrants further investigations, which may provide insights into targeting microbiota as a therapeutic strategy for ocular diseases and other diseases associated with gut microbiota in a similar paradigm.

\section{AUTHOR CONTRIBUTIONS}

WX read the literature related to the topic and participated in drafting the manuscript. JL participated in searching literature and revising the manuscript. YZ and BZ prepared figures. LW participated in the design, revision, and final approval of the manuscript. All authors read and approved the final manuscript.

Baden, T., Berens, P., Franke, K., Roman Roson, M., Bethge, M., and Euler, T. (2016). The Functional Diversity of Retinal Ganglion Cells in the Mouse. Nature 529, 345-350. doi: 10.1038/nature16468

Baggia, S., Lyons, J. L., Angell, E., Barkhuizen, A., Han, Y. B., Planck, S. R., et al. (1997). A Novel Model of Bacterially-Induced Acute Anterior Uveitis in Rats and the Lack of Effect From HLA-B27 Expression. J. Investig. Med. 45, 295-301.

Baim, A. D., Movahedan, A., Farooq, A. V., and Skondra, D. (2019). The Microbiome and Ophthalmic Disease. Exp. Biol. Med. (Maywood) 244, 419429. doi: $10.1177 / 1535370218813616$

Berer, K., Gerdes, L. A., Cekanaviciute, E., Jia, X., Xiao, L., Xia, Z., et al. (2017). Gut Microbiota From Multiple Sclerosis Patients Enables Spontaneous Autoimmune Encephalomyelitis in Mice. Proc. Natl. Acad. Sci. U. S. A. 114, 10719-10724. doi: 10.1073/pnas.1711233114

Bernstein, C. N., and Forbes, J. D. (2017). Gut Microbiome in Inflammatory Bowel Disease and Other Chronic Immune-Mediated Inflammatory Diseases. Inflamm. Intest. Dis. 2, 116-123. doi: 10.1159/000481401

Berthelot, J. M., Le Goff, B., Martin, J., Maugars, Y., and Josien, R. (2015). Essential Role for CD103+ Cells in the Pathogenesis of Spondyloarthritides. Joint Bone Spine 82, 8-12. doi: 10.1016/j.jbspin.2014.07.011

Bodis, G., Toth, V., and Schwarting, A. (2018). Role of Human Leukocyte Antigens (HLA) in Autoimmune Diseases. Methods Mol. Biol. 1802, 11-29. doi: 10.1007/ 978-1-4939-8546-3_2

Both, T., Dalm, V. A., van Hagen, P. M., and Daele, P. L. (2017). Reviewing Primary Sjögren's Syndrome: Beyond the Dryness - From Pathophysiology to Diagnosis and Treatment. Int. J. Med. Sci. 14, 191-200. doi: 10.7150/ijms.17718

Burucoa, C., and Axon, A. (2017). Epidemiology of Helicobacter Pylori Infection. Helicobacter 22 (Suppl 1), 1-5. doi: 10.1111/hel.12403

Caputi, V., and Giron, M. C. (2018). Microbiome-Gut-Brain Axis and Toll-Like Receptors in Parkinson's Disease. Int. J. Mol. Sci. 19, 1689. doi: 10.3390/ ijms 19061689

Caspi, R. R. (2010). A Look at Autoimmunity and Inflammation in the Eye. J. Clin. Invest. 120, 3073-3083. doi: 10.1172/JCI42440

Cavuoto, K. M., Mendez, R., Miller, D., Galor, A., and Banerjee, S. (2018). Effect of Clinical Parameters on the Ocular Surface Microbiome in Children and Adults. Clin. Ophthalmol. 12, 1189-1197. doi: 10.2147/OPTH.S166547

Chang, J. H., Hampartzoumian, T., Everett, B., Lloyd, A., McCluskey, P. J., and Wakefield, D. (2007). Changes in Toll-Like Receptor (TLR)-2 and TLR4 Expression and Function But Not Polymorphisms are Associated With Acute Anterior Uveitis. Invest. Ophthalmol. Vis. Sci. 48, 1711-1717. doi: 10.1167/iovs.06-0807

Chapman, N. A., Jacobs, R. J., and Braakhuis, A. J. (2019). Role of Diet and Food Intake in Age-Related Macular Degeneration: A Systematic Review. Clin. Exp. Ophthalmol. 47, 106-127. doi: 10.1111/ceo.13343

Chen, H., Cho, K. S., Vu, T. H. K., Shen, C. H., Kaur, M., Chen, G., et al. (2018). Commensal Microflora-Induced T Cell Responses Mediate Progressive Neurodegeneration in Glaucoma. Nat. Commun. 9, 3209. doi: 10.1038/ s41467-018-05681-9

Cheng, K., Ning, Z., Zhang, X., Li, L., Liao, B., Mayne, J., et al. (2017). MetaLab: An Automated Pipeline for Metaproteomic Data Analysis. Microbiome 5, 157. doi: 10.1186/s40168-017-0375-2 
Chew, E. Y., Clemons, T. E., Agrón, E., Launer, L. J., Grodstein, F., and Bernstein, P. S. (2015). Effect of Omega-3 Fatty Acids, Lutein/Zeaxanthin, or Other Nutrient Supplementation on Cognitive Function: The AREDS2 Randomized Clinical Trial. Jama 314, 791-801. doi: 10.1001/jama.2015.9677

Chibbar, R., and Dieleman, L. A. (2019). The Gut Microbiota in Celiac Disease and Probiotics. Nutrients 11, 2375. doi: 10.3390/nu11102375

Chisari, G., Chisari, E. M., Borzi, A. M., and Chisari, C. G. (2017). Aging Eye Microbiota in Dry Eye Syndrome in Patients Treated With Enterococcus Faecium and Saccharomyces Boulardii. Curr. Clin. Pharmacol. 12, 99-105. doi: 10.2174/1574884712666170704145046

Chmiela, M., and Michetti, P. (2006). Inflammation, Immunity, Vaccines for Helicobacter Infection. Helicobacter. 11 (Suppl 1), 21-26. doi: 10.1111/j.1478405X.2006.00422.x

Choi, S. H., Oh, J. W., Ryu, J. S., Kim, H. M., Im, S. H., Kim, K. P., et al. (2020). IRT5 Probiotics Changes Immune Modulatory Protein Expression in the Extraorbital Lacrimal Glands of an Autoimmune Dry Eye Mouse Model. Invest. Ophthalmol. Vis. Sci. 61, 42. doi: 10.1167/iovs.61.3.42

Chowdhury, S. R., King, D. E., Willing, B. P., Band, M. R., Beever, J. E., Lane, A. B., et al. (2007). Transcriptome Profiling of the Small Intestinal Epithelium in Germfree Versus Conventional Piglets. BMC Genom. 8, 215. doi: 10.1186/ 1471-2164-8-215

Clarridge, J. E.3rd. (2004). Impact of 16S rRNA Gene Sequence Analysis for Identification of Bacteria on Clinical Microbiology and Infectious Diseases. Clin. Microbiol. Rev. 17, 840-862. doi: 10.1128/CMR.17.4.840-862.2004

Coker, O. O., Wu, W. K. K., Wong, S. H., Sung, J. J. Y., and Yu, J. (2020). Altered Gut Archaea Composition and Interaction With Bacteria are Associated With Colorectal Cancer. Gastroenterology 159, 1459-1470 e1455. doi: 10.1053/ j.gastro.2020.06.042

Colmegna, I., Cuchacovich, R., and Espinoza, L. R. (2004). HLA-B27-Associated Reactive Arthritis: Pathogenetic and Clinical Considerations. Clin. Microbiol. Rev. 17, 348-369. doi: 10.1128/CMR.17.2.348-369.2004

Commisso, M., Strazzer, P., Toffali, K., Stocchero, M., and Guzzo, F. (2013). Untargeted Metabolomics: An Emerging Approach to Determine the Composition of Herbal Products. Comput. Struct. Biotechnol. J. 4, e201301007. doi: 10.5936/csbj.201301007

Cone, R. E., and Pais, R. (2009). Anterior Chamber-Associated Immune Deviation (ACAID): An Acute Response to Ocular Insult Protects From Future ImmuneMediated Damage? Ophthalmol. Eye Dis. 1, 33-40. doi: 10.4137/OED.S2858

Cruz, C. S., Cohen, E. J., Rapuano, C. J., and Laibson, P. R. (1998). Microbial Keratitis Resulting in Loss of the Eye. Ophthalmic Surg. Lasers 29, 803-807. doi: 10.3928/1542-8877-19981001-04

Cryan, J. F., O'Riordan, K. J., Cowan, C. S. M., Sandhu, K. V., Bastiaanssen, T. F. S., Boehme, M., et al. (2019). The Microbiota-Gut-Brain Axis. Physiol. Rev. 99, 1877-2013. doi: 10.1152/physrev.00018.2018

Daliri, E. B., Ofosu, F. K., Chelliah, R., Lee, B. H., An, H., Elahi, F., et al. (2020). Influence of Fermented Soy Protein Consumption on Hypertension and Gut Microbial Modulation in Spontaneous Hypertensive Rats. Biosci. Microbiota Food Health 39, 199-208. doi: 10.12938/bmfh.2020-001

Daliri, E. B., Ofosu, F. K., Chelliah, R., Lee, B. H., and Oh, D. H. (2021). Challenges and Perspective in Integrated Multi-Omics in Gut Microbiota Studies. Biomolecules 11, 300. doi: 10.3390/biom 11020300

Daliri, E. B., Wei, S., Oh, D. H., and Lee, B. H. (2017). The Human Microbiome and Metabolomics: Current Concepts and Applications. Crit. Rev. Food Sci. Nutr. 57, 3565-3576. doi: 10.1080/10408398.2016.1220913

Damgaard, C., Magnussen, K., Enevold, C., Nilsson, M., Tolker-Nielsen, T., Holmstrup, P., et al. (2015). Viable Bacteria Associated With Red Blood Cells and Plasma in Freshly Drawn Blood Donations. PLoS One 10, e0120826. doi: 10.1371/journal.pone.0120826

Danesh-Meyer, H. V. (2011). Neuroprotection in Glaucoma: Recent and Future Directions. Curr. Opin. Ophthalmol. 22, 78-86. doi: 10.1097/ICU.0b013e32834372ec

Deng, Y., Ge, X., Li, Y., Zou, B., Wen, X., Chen, W., et al. (2021). Identification of an Intraocular Microbiota. Cell Discov. 7, 13. doi: 10.1038/s41421-021-00245-6

Dennis-Wall, J. C., Culpepper, T., Nieves, C.Jr., Rowe, C. C., Burns, A. M., Rusch, C. T., et al. (2017). Probiotics (Lactobacillus Gasseri KS-13, Bifidobacterium Bifidum G9-1, and Bifidobacterium Longum MM-2) Improve Rhinoconjunctivitis-Specific Quality of Life in Individuals With Seasonal Allergies: A Double-Blind, Placebo-Controlled, Randomized Trial. Am. J. Clin. Nutr. 105, 758-767. doi: 10.3945/ajcn.116.140012 de Paiva, C. S., Jones, D. B., Stern, M. E., Bian, F., Moore, Q. L., Corbiere, S., et al. (2016). Altered Mucosal Microbiome Diversity and Disease Severity in Sjögren Syndrome. Sci. Rep. 6, 23561. doi: 10.1038/srep23561

Deshpande, N., Lalitha, P., Krishna das, S. R., Jethani, J., Pillai, R. M., Robin, A., et al. (2008). Helicobacter Pylori IgG Antibodies in Aqueous Humor and Serum of Subjects With Primary Open Angle and Pseudo-Exfoliation Glaucoma in a South Indian Population. J. Glaucoma 17, 605-610. doi: 10.1097/ IJG.0b013e318166f00b

Dong, X., Pan, P., Zheng, D. W., Bao, P., Zeng, X., and Zhang, X. Z. (2020). Bioinorganic Hybrid Bacteriophage for Modulation of Intestinal Microbiota to Remodel Tumor-Immune Microenvironment Against Colorectal Cancer. Sci. Adv. 6, eaba1590. doi: 10.1126/sciadv.aba1590

Dong, X., Wang, Y., Wang, W., Lin, P., and Huang, Y. (2019). Composition and Diversity of Bacterial Community on the Ocular Surface of Patients With Meibomian Gland Dysfunction. Invest. Ophthalmol. Vis. Sci. 60, 4774-4783. doi: 10.1167/iovs.19-27719

Drago, L., Toscano, M., De Grandi, R., Casini, V., and Pace, F. (2016). Persisting Changes of Intestinal Microbiota After Bowel Lavage and Colonoscopy. Eur. J. Gastroenterol. Hepatol. 28, 532-537. doi: 10.1097/MEG.0000000000000581

Dzidic, M., Boix-Amorós, A., Selma-Royo, M., Mira, A., and Collado, M. C. (2018). Gut Microbiota and Mucosal Immunity in the Neonate. Med. Sci. (Basel) 6 (3), 56

Easterly, C. W., Sajulga, R., Mehta, S., Johnson, J., Kumar, P., Hubler, S., et al. (2019). Metaquantome: An Integrated, Quantitative Metaproteomics Approach Reveals Connections Between Taxonomy and Protein Function in Complex Microbiomes. Mol. Cell. Proteom. 18, S82-S91. doi: 10.1074/ mcp.RA118.001240

Eguchi, H., Hotta, F., Kuwahara, T., Imaohji, H., Miyazaki, C., Hirose, M., et al. (2017a). Diagnostic Approach to Ocular Infections Using Various Techniques From Conventional Culture to Next-Generation Sequencing Analysis. Cornea 36 (Suppl 1), S46-s52. doi: 10.1097/ICO.0000000000001338

Eguchi, H., Hotta, F., Kuwahara, T., Nakayama-Imaohji, H., Kusaka, S., and Shimomura, Y. (2017b). Acute Keratoconjunctivitis Due to Contamination of Contact Lens Care Solution With Histamine-Producing Raoultella Species: A Case Report. Med. (Baltimore) 96, e9310. doi: 10.1097/MD.0000000000009310

Eisenstein, E. M., and Williams, C. B. (2009). The T(reg)/Th17 Cell Balance: A New Paradigm for Autoimmunity. Pediatr. Res. 65, 26R-31R. doi: 10.1203/ PDR.0b013e31819e76c7

Emerson, J. B., Adams, R. I., Román, C. M. B., Brooks, B., Coil, D. A., Dahlhausen, K., et al. (2017). Schrödinger's Microbes: Tools for Distinguishing the Living From the Dead in Microbial Ecosystems. Microbiome 5, 86. doi: 10.1186/ s40168-017-0285-3

Ericsson, A. C., and Franklin, C. L. (2015). Manipulating the Gut Microbiota: Methods and Challenges. Ilar J. 56, 205-217. doi: 10.1093/ilar/ilv021

Fernández-Rubio, M. E., Rebolledo-Lara, L., Martinez-García, M., AlarcónTomás, M., and Cortés-Valdés, C. (2010). The Conjunctival Bacterial Pattern of Diabetics Undergoing Cataract Surgery. Eye (London) 24, 825-834. doi: 10.1038/eye.2009.218

Flemming, A. (2018). Bacteria-Primed T Cells Identified as Culprit in Glaucoma. Nat. Rev. Immunol. 18, 603. doi: 10.1038/s41577-018-0063-x

Forrester, J. V., Klaska, I. P., Yu, T., and Kuffova, L. (2013). Uveitis in Mouse and Man. Int. Rev. Immunol. 32, 76-96. doi: 10.3109/08830185.2012.747524

Forslund, K., Hildebrand, F., Nielsen, T., Falony, G., Le Chatelier, E., Sunagawa, S., et al. (2015). Disentangling Type 2 Diabetes and Metformin Treatment Signatures in the Human Gut Microbiota. Nature 528, 262-266. doi: $10.1038 /$ nature 15766

Franzosa, E. A., Morgan, X. C., Segata, N., Waldron, L., Reyes, J., Earl, A. M., et al. (2014). Relating the Metatranscriptome and Metagenome of the Human Gut. Proc. Natl. Acad. Sci. U. S. A. 111, E2329-E2338. doi: 10.1073/pnas.1319284111

Gaboriau-Routhiau, V., Rakotobe, S., Lécuyer, E., Mulder, I., Lan, A., Bridonneau, C., et al. (2009). The Key Role of Segmented Filamentous Bacteria in the Coordinated Maturation of Gut Helper T Cell Responses. Immunity 31, 677689. doi: 10.1016/j.immuni.2009.08.020

Galloway, P. H., Warner, S. J., Morshed, M. G., and Mikelberg, F. S. (2003). Helicobacter Pylori Infection and the Risk for Open-Angle Glaucoma. Ophthalmology 110, 922-925. doi: 10.1016/S0161-6420(03)00093-9

Gavin, P. G., Mullaney, J. A., Loo, D., Cao, K. L., Gottlieb, P. A., Hill, M. M., et al. (2018). Intestinal Metaproteomics Reveals Host-Microbiota Interactions in 
Subjects at Risk for Type 1 Diabetes. Diabetes Care 41, 2178-2186. doi: $10.2337 / \mathrm{dc} 18-0777$

Geyer, O., and Levo, Y. (2020). Glaucoma is an Autoimmune Disease. Autoimmun. Rev. 19, 102535. doi: 10.1016/j.autrev.2020.102535

Ghaisas, S., Maher, J., and Kanthasamy, A. (2016). Gut Microbiome in Health and Disease: Linking the Microbiome-Gut-Brain Axis and Environmental Factors in the Pathogenesis of Systemic and Neurodegenerative Diseases. Pharmacol. Ther. 158, 52-62. doi: 10.1016/j.pharmthera.2015.11.012

Gong, H., Zhang, S., Li, Q., Zuo, C., Gao, X., Zheng, B., et al. (2020). Gut Microbiota Compositional Profile and Serum Metabolic Phenotype in Patients With Primary Open-Angle Glaucoma. Exp. Eye Res. 191, 107921. doi: 10.1016/ j.exer.2020.107921

Gorkiewicz, G., Thallinger, G. G., Trajanoski, S., Lackner, S., Stocker, G., Hinterleitner, T., et al. (2013). Alterations in the Colonic Microbiota in Response to Osmotic Diarrhea. PLoS One 8, e55817. doi: 10.1371/journal.pone.0055817

Graham, J. E., Moore, J. E., Jiru, X., Moore, J. E., Goodall, E. A., Dooley, J. S., et al. (2007). Ocular Pathogen or Commensal: A PCR-Based Study of Surface Bacterial Flora in Normal and Dry Eyes. Invest. Ophthalmol. Vis. Sci. 48, 5616-5623. doi: 10.1167/iovs.07-0588

Granata, I., Nardelli, C., D'Argenio, V., Tramontano, S., Compare, D., Guarracino, M. R., et al. (2020). Duodenal Metatranscriptomics to Define Human and Microbial Functional Alterations Associated With Severe Obesity: A Pilot Study. Microorganisms 8, 1811. doi: 10.3390/microorganisms8111811

Gray, D. H., Gavanescu, I., Benoist, C., and Mathis, D. (2007). Danger-Free Autoimmune Disease in AIRE-Deficient Mice. Proc. Natl. Acad. Sci. U. S. A. 104, 18193-18198. doi: 10.1073/pnas.0709160104

Graziani, F., Pujol, A., Nicoletti, C., Dou, S., Maresca, M., Giardina, T., et al. (2016). Ruminococcus Gnavus E1 Modulates Mucin Expression and Intestinal Glycosylation. J. Appl. Microbiol. 120, 1403-1417. doi: 10.1111/jam.13095

Gregory, A. C., Zablocki, O., Zayed, A. A., Howell, A., Bolduc, B., and Sullivan, M. B. (2020). The Gut Virome Database Reveals Age-Dependent Patterns of Virome Diversity in the Human Gut. Cell Host Microbe 28, 724-740.e728. doi: 10.1016/j.chom.2020.08.003

Greiling, T. M., Dehner, C., Chen, X., Hughes, K., Iñiguez, A. J., Boccitto, M., et al. (2018). Commensal Orthologs of the Human Autoantigen Ro60 as Triggers of Autoimmunity in Lupus. Sci. Transl. Med. 10, eaan2306. doi: 10.1126/ scitranslmed.aan2306

Gritz, D. C., and Wong, I. G. (2004). Incidence and Prevalence of Uveitis in Northern California; the Northern California Epidemiology of Uveitis Study. Ophthalmology 111, 491-500. doi: 10.1016/j.ophtha.2003.06.014

Guo, J., Yan, T., Bi, H., Xie, X., Wang, X., Guo, D., et al. (2014). Plasma Metabonomics Study of the Patients With Acute Anterior Uveitis Based on Ultra-Performance Liquid Chromatography-Mass Spectrometry. Graefes Arch. Clin. Exp. Ophthalmol. 252, 925-934. doi: 10.1007/s00417-014-2619-1

Handa, J. T., Bowes Rickman, C., Dick, A. D., Gorin, M. B., Miller, J. W., Toth, C. A., et al. (2019). A Systems Biology Approach Towards Understanding and Treating non-Neovascular Age-Related Macular Degeneration. Nat. Commun. 10, 3347. doi: 10.1038/s41467-019-11262-1

Hasegawa, Y., Fujitani, M., Hata, K., Tohyama, M., Yamagishi, S., and Yamashita, T. (2004). Promotion of Axon Regeneration by Myelin-Associated Glycoprotein and Nogo Through Divergent Signals Downstream of Gi/G. J. Neurosci. 24, 6826-6832. doi: 10.1523/JNEUROSCI.1856-04.2004

Heintz-Buschart, A., May, P., Laczny, C. C., Lebrun, L. A., Bellora, C., Krishna, A., et al. (2016). Integrated Multi-Omics of the Human Gut Microbiome in a Case Study of Familial Type 1 Diabetes. Nat. Microbiol. 2, 16180. doi: 10.1038/ nmicrobiol.2016.180

Henke, M. T., Kenny, D. J., Cassilly, C. D., Vlamakis, H., Xavier, R. J., and Clardy, J. (2019). Ruminococcus Gnavus, a Member of the Human Gut Microbiome Associated With Crohn's Disease, Produces an Inflammatory Polysaccharide. Proc. Natl. Acad. Sci. U. S. A. 116, 12672-12677. doi: 10.1073/ pnas. 1904099116

Hoekzema, R., Verhagen, C., van Haren, M., and Kijlstra, A. (1992). EndotoxinInduced Uveitis in the Rat. The Significance of Intraocular Interleukin-6. Invest. Ophthalmol. Vis. Sci. 33, 532-539.

Horai, R., and Caspi, R. R. (2019). Microbiome and Autoimmune Uveitis. Front. Immunol. 10, 232. doi: 10.3389/fimmu.2019.00232

Horai, R., Silver, P. B., Chen, J., Agarwal, R. K., Chong, W. P., Jittayasothorn, Y., et al. (2013). Breakdown of Immune Privilege and Spontaneous Autoimmunity in Mice Expressing a Transgenic T Cell Receptor Specific for a Retinal Autoantigen. J. Autoimmun. 44, 21-33. doi: 10.1016/j.jaut.2013.06.003

Horai, R., Zárate-Bladés, C. R., Dillenburg-Pilla, P., Chen, J., Kielczewski, J. L., Silver, P. B., et al. (2015). Microbiota-Dependent Activation of an Autoreactive T Cell Receptor Provokes Autoimmunity in an Immunologically Privileged Site. Immunity 43, 343-353. doi: 10.1016/j.immuni.2015.07.014

Hori, Y., Maeda, N., Sakamoto, M., Koh, S., Inoue, T., and Tano, Y. (2008). Bacteriologic Profile of the Conjunctiva in the Patients With Dry Eye. Am. J. Ophthalmol. 146, 729-734. doi: 10.1016/j.ajo.2008.06.003

Hornef, M. W., and Pabst, O. (2016). Real Friends: Faecalibacterium Prausnitzii Supports Mucosal Immune Homeostasis. Gut 65, 365-367. doi: 10.1136/gutjnl2015-310027

Hsu, B. B., Gibson, T. E., Yeliseyev, V., Liu, Q., Lyon, L., Bry, L., et al. (2019). Dynamic Modulation of the Gut Microbiota and Metabolome by Bacteriophages in a Mouse Model. Cell Host Microbe 25, 803-814.e805. doi: 10.1016/j.chom.2019.05.001

Huang, Y., Yang, B., and Li, W. (2016). Defining the Normal Core Microbiome of Conjunctival Microbial Communities. Clin. Microbiol. Infect. 22, 643.e647643.e612. doi: 10.1016/j.cmi.2016.04.008

Huang, X., Ye, Z., Cao, Q., Su, G., Wang, Q., Deng, J., et al. (2018). Gut Microbiota Composition and Fecal Metabolic Phenotype in Patients With Acute Anterior Uveitis. Invest. Ophthalmol. Vis. Sci. 59, 1523-1531. doi: 10.1167/iovs.17-22677

Ivanov, I. I., Atarashi, K., Manel, N., Brodie, E. L., Shima, T., Karaoz, U., et al. (2009). Induction of Intestinal Th17 Cells by Segmented Filamentous Bacteria. Cell 139, 485-498. doi: 10.1016/j.cell.2009.09.033

Jabs, D. A., Nussenblatt, R. B., Rosenbaum, J. T.Standardization of Uveitis Nomenclature Working, G (2005). Standardization of Uveitis Nomenclature for Reporting Clinical Data. Results of the First International Workshop. Am. J. Ophthalmol. 140, 509-516. doi: 10.1016/j.ajo.2005.03.057

Jagtap, P. D., Blakely, A., Murray, K., Stewart, S., Kooren, J., Johnson, J. E., et al. (2015). Metaproteomic Analysis Using the Galaxy Framework. Proteomics 15, 3553-3565. doi: 10.1002/pmic.201500074

Jangi, S., Gandhi, R., Cox, L. M., Li, N., von Glehn, F., Yan, R., et al. (2016). Alterations of the Human Gut Microbiome in Multiple Sclerosis. Nat. Commun. 7, 12015. doi: 10.1038/ncomms12015

Janowitz, C., Nakamura, Y. K., Metea, C., Gligor, A., Yu, W., Karstens, L., et al. (2019). Disruption of Intestinal Homeostasis and Intestinal Microbiota During Experimental Autoimmune Uveitis. Invest. Ophthalmol. Vis. Sci. 60, 420-429. doi: $10.1167 /$ iovs.18-24813

Jia, Y., Leung, M. H. Y., Tong, X., Wilkins, D., and Lee, P. K. H. (2019). Rare Taxa Exhibit Disproportionate Cell-Level Metabolic Activity in Enriched Anaerobic Digestion Microbial Communities. mSystems 4, e00208-e00218. doi: 10.1128/ mSystems.00208-18

Jiang, X., Deng, A., Yang, J., Bai, H., Yang, Z., Wu, J., et al. (2018). Pathogens in the Meibomian Gland and Conjunctival Sac: Microbiome of Normal Subjects and Patients With Meibomian Gland Dysfunction. Infect. Drug Resist. 11, 17291740. doi: 10.2147/IDR.S162135

Jiang, Y., Xiong, X., Danska, J., and Parkinson, J. (2016). Metatranscriptomic Analysis of Diverse Microbial Communities Reveals Core Metabolic Pathways and Microbiome-Specific Functionality. Microbiome 4, 2. doi: 10.1186/s40168015-0146- $\mathrm{x}$

Jin, P., and Wang, E. (2003). Polymorphism in Clinical Immunology - From HLA Typing to Immunogenetic Profiling. J. Transl. Med. 1, 8. doi: 10.1186/14795876-1-8

Kalyana Chakravarthy, S., Jayasudha, R., Sai Prashanthi, G., Ali, M. H., Sharma, S., Tyagi, M., et al. (2018). Dysbiosis in the Gut Bacterial Microbiome of Patients With Uveitis, an Inflammatory Disease of the Eye. Indian J. Microbiol. 58, $457-$ 469. doi: 10.1007/s12088-018-0746-9

Kamada, N., Seo, S. U., Chen, G. Y., and Nunez, G. (2013). Role of the Gut Microbiota in Immunity and Inflammatory Disease. Nat. Rev. Immunol. 13, 321-335. doi: 10.1038/nri3430

Karlsson, F. H., Tremaroli, V., Nookaew, I., Bergström, G., Behre, C. J., Fagerberg, B., et al. (2013). Gut Metagenome in European Women With Normal, Impaired and Diabetic Glucose Control. Nature 498, 99-103. doi: 10.1038/nature12198

Kell, D., Potgieter, M., and Pretorius, E. (2015). Individuality, Phenotypic Differentiation, Dormancy and 'Persistence' in Culturable Bacterial Systems: Commonalities Shared by Environmental, Laboratory, and Clinical Microbiology. F1000Res 4, 179. doi: 10.12688/f1000research.6709.2 
Khan, M. A. (2008). HLA-B27 and its Pathogenic Role. J. Clin. Rheumatol. 14, 5052. doi: $10.1097 /$ RHU.0b013e3181637a38

Kho, Z. Y., and Lal, S. K. (2018). The Human Gut Microbiome - a Potential Controller of Wellness and Disease. Front. Microbiol. 9, 1835. doi: 10.3389/ fmicb.2018.01835

Kim, J., Choi, S. H., Kim, Y. J., Jeong, H. J., Ryu, J. S., Lee, H. J., et al. (2017). Clinical Effect of IRT-5 Probiotics on Immune Modulation of Autoimmunity or Alloimmunity in the Eye. Nutrients 9 (11), 1166. doi: 10.3390/nu9111166

Klenkler, B., and Sheardown, H. (2004). Growth Factors in the Anterior Segment: Role in Tissue Maintenance, Wound Healing and Ocular Pathology. Exp. Eye Res. 79, 677-688. doi: 10.1016/j.exer.2004.07.008

Knop, E., and Knop, N. (2007). Anatomy and Immunology of the Ocular Surface. Chem. Immunol. Allergy 92, 36-49. doi: 10.1159/000099252

Korobelnik, J. F., Kleijnen, J., Lang, S. H., Birnie, R., Leadley, R. M., Misso, K., et al. (2015). Systematic Review and Mixed Treatment Comparison of Intravitreal Aflibercept With Other Therapies for Diabetic Macular Edema (DME). BMC Ophthalmol. 15, 52. doi: 10.1186/s12886-015-0035-x

Kountouras, J., Mylopoulos, N., Boura, P., Bessas, C., Chatzopoulos, D., Venizelos, J., et al. (2001). Relationship Between Helicobacter Pylori Infection and Glaucoma. Ophthalmology 108, 599-604. doi: 10.1016/S0161-6420(00)00598-4

Kugadas, A., Christiansen, S. H., Sankaranarayanan, S., Surana, N. K., Gauguet, S., Kunz, R., et al. (2016). Impact of Microbiota on Resistance to Ocular Pseudomonas Aeruginosa-Induced Keratitis. PLoS Pathog. 12, e1005855. doi: 10.1371/journal.ppat.1005855

Kugadas, A., Wright, Q., Geddes-McAlister, J., and Gadjeva, M. (2017). Role of Microbiota in Strengthening Ocular Mucosal Barrier Function Through Secretory IgA. Invest. Ophthalmol. Vis. Sci. 58, 4593-4600. doi: 10.1167/ iovs.17-22119

Kuklinski, E., and Asbell, P. A. (2017). Sjogren's Syndrome From the Perspective of Ophthalmology. Clin. Immunol. 182, 55-61. doi: 10.1016/ j.clim.2017.04.017

Kurtz, S., Regenbogen, M., Goldiner, I., Horowitz, N., and Moshkowitz, M. (2008). No Association Between Helicobacter Pylori Infection or CagA-Bearing Strains and Glaucoma. J. Glaucoma 17, 223-226. doi: 10.1097/IJG.0b013e31815a34ac

Lee, R. W., Nicholson, L. B., Sen, H. N., Chan, C. C., Wei, L., Nussenblatt, R. B., et al. (2014). Autoimmune and Autoinflammatory Mechanisms in Uveitis. Semin. Immunopathol. 36, 581-594. doi: 10.1007/s00281-014-0433-9

Lee, S. H., Oh, D. H., Jung, J. Y., Kim, J. C., and Jeon, C. O. (2012). Comparative Ocular Microbial Communities in Humans With and Without Blepharitis. Invest. Ophthalmol. Vis. Sci. 53, 5585-5593. doi: 10.1167/iovs.12-9922

Liang, S. T., Xu, Y. C., Dennis, P., and Bremer, H. (2000). mRNA Composition and Control of Bacterial Gene Expression. J. Bacteriol. 182, 3037-3044. doi: 10.1128/JB.182.11.3037-3044.2000

Libby, R. T., Anderson, M. G., Pang, I. H., Robinson, Z. H., Savinova, O. V., Cosma, I. M., et al. (2005). Inherited Glaucoma in DBA/2J Mice: Pertinent Disease Features for Studying the Neurodegeneration. Vis. Neurosci. 22, 637648. doi: $10.1017 /$ S0952523805225130

Lin, P. (2018). The Role of the Intestinal Microbiome in Ocular Inflammatory Disease. Curr. Opin. Ophthalmol. 29, 261-266. doi: 10.1097/ ICU.0000000000000465

Lin, P. (2019). Importance of the Intestinal Microbiota in Ocular Inflammatory Diseases: A Review. Clin. Exp. Ophthalmol. 47, 418-422. doi: 10.1111/ ceo. 13493

Li, J. J., Yi, S., and Wei, L. (2020). Ocular Microbiota and Intraocular Inflammation. Front. Immunol. 11, 609765. doi: 10.3389/fimmu.2020.609765

Lobato, R. D. (2008). Historical Vignette of Cajal's Work "Degeneration and Regeneration of the Nervous System" With a Reflection of the Author. Neurocirugia 19, 456-468. doi: 10.1016/S1130-1473(08)70215-X

Long, S., Yang, Y., Shen, C., Wang, Y., Deng, A., Qin, Q., et al. (2020). Metaproteomics Characterizes Human Gut Microbiome Function in Colorectal Cancer. NPJ Biofilms Microbiomes 6, 14. doi: 10.1038/s41522-020-0123-4

Lorenzon, R., Mariotti-Ferrandiz, E., Aheng, C., Ribet, C., Toumi, F., Pitoiset, F., et al. (2018). Clinical and Multi-Omics Cross-Phenotyping of Patients With Autoimmune and Autoinflammatory Diseases: The Observational TRANSIMMUNOM Protocol. BMJ Open 8, e021037. doi: 10.1136/bmjopen2017-021037

Luissint, A. C., Parkos, C. A., and Nusrat, A. (2016). Inflammation and the Intestinal Barrier: Leukocyte-Epithelial Cell Interactions, Cell Junction
Remodeling, and Mucosal Repair. Gastroenterology 151, 616-632. doi: 10.1053/j.gastro.2016.07.008

Lu, L. J., and Liu, J. (2016). Human Microbiota and Ophthalmic Disease. Yale J. Biol. Med. 89, 325-330.

Lusthaus, J., and Goldberg, I. (2019). Current Management of Glaucoma. Med. J. Aust. 210, 180-187. doi: 10.5694/mja2.50020

Mathewson, N. D., Jenq, R., Mathew, A. V., Koenigsknecht, M., Hanash, A., Toubai, T., et al. (2016). Gut Microbiome-Derived Metabolites Modulate Intestinal Epithelial Cell Damage and Mitigate Graft-Versus-Host Disease. Nat. Commun. 17, 505-513. doi: 10.1038/ni.3400

Maurice, C. F., Haiser, H. J., and Turnbaugh, P. J. (2013). Xenobiotics Shape the Physiology and Gene Expression of the Active Human Gut Microbiome. Cell 152, 39-50. doi: 10.1016/j.cell.2012.10.052

Mayers, M. D., Moon, C., Stupp, G. S., Su, A. I., and Wolan, D. W. (2017). Quantitative Metaproteomics and Activity-Based Probe Enrichment Reveals Significant Alterations in Protein Expression From a Mouse Model of Inflammatory Bowel Disease. J. Proteome Res. 16, 1014-1026. doi: 10.1021/ acs.jproteome.6b00938

Mendez, R., Watane, A., Farhangi, M., Cavuoto, K. M., Leith, T., Budree, S., et al. (2020). Gut Microbial Dysbiosis in Individuals With Sjögren's Syndrome. Microb. Cell Fact. 19, 90. doi: 10.1186/s12934-020-01348-7

Mesuere, B., Willems, T., van der Jeugt, F., Devreese, B., Vandamme, P., and Dawyndt, P. (2016). Unipept Web Services for Metaproteomics Analysis. Bioinformatics 32, 1746-1748. doi: 10.1093/bioinformatics/btw039

Międzybrodzki, R., Borysowski, J., Kłak, M., Jończyk-Matysiak, E., ObmińskaMrukowicz, B., Suszko-Pawłowska, A., et al. (2017). In Vivo Studies on the Influence of Bacteriophage Preparations on the Autoimmune Inflammatory Process. Biomed. Res. Int. 2017, 3612015. doi: 10.1155/2017/3612015

Miller, D., and Iovieno, A. (2009). The Role of Microbial Flora on the Ocular Surface. Curr. Opin. Allergy Clin. Immunol. 9, 466-470. doi: 10.1097/ ACI.0b013e3283303elb

Miyazaki, D., Eguchi, H., Kuwahara, T., Nakayama-Imaohji, H., Inaba, M., Itoi, M., et al. (2020). Presence of Acanthamoeba and Diversified Bacterial Flora in Poorly Maintained Contact Lens Cases. Sci. Rep. 10, 12595. doi: 10.1038/ s41598-020-69554-2

Moon, J., Choi, S. H., Yoon, C. H., and Kim, M. K. (2020). Gut Dysbiosis is Prevailing in Sjögren's Syndrome and is Related to Dry Eye Severity. PLoS One 15, e0229029. doi: 10.1371/journal.pone.0229029

Morais, L. H., Schreiber, H., and Mazmanian, S. K. (2021). The Gut MicrobiotaBrain Axis in Behaviour and Brain Disorders. Nat. Rev. Microbiol. 19, 241-255. doi: 10.1038/s41579-020-00460-0

Morita, Y., Jounai, K., Sakamoto, A., Tomita, Y., Sugihara, Y., Suzuki, H., et al. (2018). Long-Term Intake of Lactobacillus Paracasei KW3110 Prevents AgeRelated Chronic Inflammation and Retinal Cell Loss in Physiologically Aged Mice. Aging (Albany NY) 10, 2723-2740. doi: 10.18632/aging.101583

Mshangila, B., Paddy, M., Kajumbula, H., Ateenyi-Agaba, C., Kahwa, B., and Seni, J. (2013). External Ocular Surface Bacterial Isolates and Their Antimicrobial Susceptibility Patterns Among Pre-Operative Cataract Patients at Mulago National Hospital in Kampala, Uganda. BMC Ophthalmol. 13, 71. doi: 10.1186/1471-2415-13-71

Muth, T., Kohrs, F., Heyer, R., Benndorf, D., Rapp, E., Reichl, U., et al. (2018). MPA Portable: A Stand-Alone Software Package for Analyzing Metaproteome Samples on the Go. Anal. Chem. 90, 685-689. doi: 10.1021/ acs.analchem.7b03544

Nadeem, U., Xie, B., Movahedan, A., D'Souza, M., Barba, H., Deng, N., et al. (2020). High Throughput RNA Sequencing of Mice Retina Reveals Metabolic Pathways Involved in the Gut-Retina Axis. bioRxiv 3, 34.

Nagata, N., Tohya, M., Fukuda, S., Suda, W., Nishijima, S., Takeuchi, F., et al. (2019). Effects of Bowel Preparation on the Human Gut Microbiome and Metabolome. Sci. Rep. 9, 4042. doi: 10.1038/s41598-019-40182-9

Nagpal, R., Neth, B. J., Wang, S., Mishra, S. P., Craft, S., and Yadav, H. (2020). Gut Mycobiome and its Interaction With Diet, Gut Bacteria and Alzheimer's Disease Markers in Subjects With Mild Cognitive Impairment: A Pilot Study. EBioMedicine 59, 102950. doi: 10.1016/j.ebiom.2020.102950

Nakamura, Y. K., Janowitz, C., Metea, C., Asquith, M., Karstens, L., Rosenbaum, J. T., et al. (2017). Short Chain Fatty Acids Ameliorate Immune-Mediated Uveitis Partially by Altering Migration of Lymphocytes From the Intestine. Sci. Rep. 7 , 11745. doi: 10.1038/s41598-017-12163-3 
Nakamura, Y. K., Metea, C., Karstens, L., Asquith, M., Gruner, H., Moscibrocki, C., et al. (2016). Gut Microbial Alterations Associated With Protection From Autoimmune Uveitis. Invest. Ophthalmol. Vis. Sci. 57, 3747-3758. doi: $10.1167 /$ iovs.16-19733

Napolitano, P., Filippelli, M., Davinelli, S., Bartollino, S., dell'Omo, R., and Costagliola, C. (2021). Influence of Gut Microbiota on Eye Diseases: An Overview. Ann. Med. 53, 750-761. doi: 10.1080/07853890.2021.1925150

Nejman, D., Livyatan, I., Fuks, G., Gavert, N., Zwang, Y., Geller, L. T., et al. (2020). The Human Tumor Microbiome is Composed of Tumor Type-Specific Intracellular Bacteria. Science 368, 973-980. doi: 10.1126/science.aay9189

Noack, M., and Miossec, P. (2014). Th17 and Regulatory T Cell Balance in Autoimmune and Inflammatory Diseases. Autoimmun. Rev. 13, 668-677. doi: 10.1016/j.autrev.2013.12.004

O'Keeffe, K. M., Wilk, M. M., Leech, J. M., Murphy, A. G., Laabei, M., Monk, I. R., et al. (2015). Manipulation of Autophagy in Phagocytes Facilitates Staphylococcus Aureus Bloodstream Infection. Infect. Immun. 83, 3445-3457. doi: 10.1128/IAI.00358-15

Olivares, M., Neef, A., Castillejo, G., Palma, G. D., Varea, V., Capilla, A., et al. (2015). The HLA-DQ2 Genotype Selects for Early Intestinal Microbiota Composition in Infants at High Risk of Developing Coeliac Disease. Gut 64, 406-417. doi: 10.1136/gutjnl-2014-306931

Olson, J. A., Forrester, M., Clohessy, P. A., Golden, B. E., Herriot, R., and Forrester, J. V. (1996). Calprotectin is Raised in Endogenous Posterior Uveitis. Ocul. Immunol. Inflamm. 4, 91-98. doi: 10.3109/09273949609079638

Ozkan, J., Nielsen, S., Diez-Vives, C., Coroneo, M., Thomas, T., and Willcox, M. (2017). Temporal Stability and Composition of the Ocular Surface Microbiome. Sci. Rep. 7, 9880. doi: 10.1038/s41598-017-10494-9

Paisse, S., Valle, C., Servant, F., Courtney, M., Burcelin, R., Amar, J., et al. (2016). Comprehensive Description of Blood Microbiome From Healthy Donors Assessed by $16 \mathrm{~S}$ Targeted Metagenomic Sequencing. Transfusion 56, 11381147. doi: 10.1111/trf.13477

Pasolli, E., Asnicar, F., Manara, S., Zolfo, M., Karcher, N., Armanini, F., et al. (2019). Extensive Unexplored Human Microbiome Diversity Revealed by Over 150,000 Genomes From Metagenomes Spanning Age, Geography, and Lifestyle. Cell 176, 649-662.e620. doi: 10.1016/j.cell.2019.01.001

Peng, B., Li, H., and Peng, X. X. (2015). Functional Metabolomics: From Biomarker Discovery to Metabolome Reprogramming. Protein Cell 6, 628637. doi: 10.1007/s13238-015-0185-x

Pianta, A., Arvikar, S. L., Strle, K., Drouin, E. E., Wang, Q., Costello, C. E., et al. (2017). Two Rheumatoid Arthritis-Specific Autoantigens Correlate Microbial Immunity With Autoimmune Responses in Joints. J. Clin. Invest. 127, 29462956. doi: 10.1172/JCI93450

Pickering, H., Palmer, C. D., Houghton, J., Makalo, P., Joof, H., Derrick, T., et al. (2019). Conjunctival Microbiome-Host Responses Are Associated With Impaired Epithelial Cell Health in Both Early and Late Stages of Trachoma. Front. Cell Infect. Microbiol. 9, 297. doi: 10.3389/fcimb.2019.00297

Pinna, A., Sechi, L. A., Zanetti, S., and Carta, F. (2005). Detection of Virulence Factors in a Corneal Isolate of Klebsiella Pneumoniae. Ophthalmology 112, 883-887. doi: 10.1016/j.ophtha.2004.12.024

Poore, G. D., Kopylova, E., Zhu, Q., Carpenter, C., Fraraccio, S., Wandro, S., et al. (2020). Microbiome Analyses of Blood and Tissues Suggest Cancer Diagnostic Approach. Nature 579, 567-574. doi: 10.1038/s41586-020-2095-1

Potgieter, M., Bester, J., Kell, D. B., and Pretorius, E. (2015). The Dormant Blood Microbiome in Chronic, Inflammatory Diseases. FEMS Microbiol. Rev. 39, 567-591. doi: 10.1093/femsre/fuv013

Proekt, I., Miller, C. N., Jeanne, M., Fasano, K. J., Moon, J. J., Lowell, C. A., et al. (2016). LYN- and AIRE-Mediated Tolerance Checkpoint Defects Synergize to Trigger Organ-Specific Autoimmunity. J. Clin. Invest. 126, 3758-3771. doi: $10.1172 /$ JCI84440

Proekt, I., Miller, C. N., Lionakis, M. S., and Anderson, M. S. (2017). Insights Into Immune Tolerance From AIRE Deficiency. Curr. Opin. Immunol. 49, 71-78. doi: 10.1016/j.coi.2017.10.003

Quigley, H. A., and Broman, A. T. (2006). The Number of People With Glaucoma Worldwide in 2010 and 2020. Br. J. Ophthalmol. 90, 262-267. doi: 10.1136/ bjo. 2005.081224

Rajilić-Stojanović, M., Jonkers, D. M., Salonen, A., Hanevik, K., Raes, J., Jalanka, J., et al. (2015). Intestinal Microbiota and Diet in IBS: Causes, Consequences, or Epiphenomena? Am. J. Gastroenterol. 110, 278-287. doi: 10.1038/ajg.2014.427
Rakover, I. S., Zabavnik, N., Kopel, R., Paz-Rozner, M., and Solomon, B. (2010). Antigen-Specific Therapy of EAE via Intranasal Delivery of Filamentous Phage Displaying a Myelin Immunodominant Epitope. J. Neuroimmunol. 225, 68-76. doi: 10.1016/j.jneuroim.2010.04.014

Rausch, P., Rühlemann, M., Hermes, B. M., Doms, S., Dagan, T., Dierking, K., et al. (2019). Comparative Analysis of Amplicon and Metagenomic Sequencing Methods Reveals Key Features in the Evolution of Animal Metaorganisms. Microbiome 7, 133. doi: 10.1186/s40168-019-0743-1

Rivière, A., Selak, M., Lantin, D., Leroy, F., and De Vuyst, L. (2016). Bifidobacteria and Butyrate-Producing Colon Bacteria: Importance and Strategies for Their Stimulation in the Human Gut. Front. Microbiol. 7, 979.

Rojas, M., Restrepo-Jiménez, P., Monsalve, D. M., Pacheco, Y., Acosta-Ampudia, Y., Ramírez-Santana, C., et al. (2018). Molecular Mimicry and Autoimmunity. J. Autoimmun. 95, 100-123. doi: 10.1016/j.jaut.2018.10.012

Rolig, A. S., Sweeney, E. G., Kaye, L. E., DeSantis, M. D., Perkins, A., Banse, A. V., et al. (2018). A Bacterial Immunomodulatory Protein With Lipocalin-Like Domains Facilitates Host-Bacteria Mutualism in Larval Zebrafish. Elife 7, e37172. doi: 10.7554/eLife.37172

Rosenbaum, J. T. (1989). Characterization of Uveitis Associated With Spondyloarthritis. J. Rheumatol. 16, 792-796.

Rosenbaum, J. T., and Asquith, M. (2018). The Microbiome and HLA-B27Associated Acute Anterior Uveitis. Nat. Rev. Rheumatol. 14, 704-713. doi: 10.1038/s41584-018-0097-2

Rowan, S., Jiang, S., Korem, T., Szymanski, J., Chang, M. L., Szelog, J., et al. (2017). Involvement of a Gut-Retina Axis in Protection Against Dietary GlycemiaInduced Age-Related Macular Degeneration. Proc. Natl. Acad. Sci. U. S. A. 114, E4472-E4481. doi: 10.1073/pnas.1702302114

Santos, T. M., Ledbetter, E. C., Caixeta, L. S., Bicalho, M. L., and Bicalho, R. C. (2011). Isolation and Characterization of Two Bacteriophages With Strong In Vitro Antimicrobial Activity Against Pseudomonas Aeruginosa Isolated From Dogs With Ocular Infections. Am. J. Vet. Res. 72, 1079-1086. doi: 10.2460/ajvr.72.8.1079

Savage, D. C., Siegel, J. E., Snellen, J. E., and Whitt, D. D. (1981). Transit Time of Epithelial Cells in the Small Intestines of Germfree Mice and Ex-Germfree Mice Associated With Indigenous Microorganisms. Appl. Environ. Microbiol. 42, 996-1001. doi: 10.1128/aem.42.6.996-1001.1981

Schabereiter-Gurtner, C., Maca, S., Rölleke, S., Nigl, K., Lukas, J., Hirschl, A., et al. (2001). 16s rDNA-Based Identification of Bacteria From Conjunctival Swabs by PCR and DGGE Fingerprinting. Invest. Ophthalmol. Vis. Sci. 42, 1164-1171.

Scher, J. U., Littman, D. R., and Abramson, S. B. (2016). Microbiome in Inflammatory Arthritis and Human Rheumatic Diseases. Arthritis. Rheumatol. 68, 35-45. doi: 10.1002/art.39259

Schierwagen, R., Alvarez-Silva, C., Madsen, M. S. A., Kolbe, C. C., Meyer, C., Thomas, D., et al. (2019). Circulating Microbiome in Blood of Different Circulatory Compartments. Gut 68, 578-580. doi: 10.1136/gutjnl-2018-316227

Schloss, P. D., and Handelsman, J. (2004). Status of the Microbial Census. Microbiol. Mol. Biol. Rev. 68, 686-691. doi: 10.1128/MMBR.68.4.686-691.2004 Schuster, A. K., Erb, C., Hoffmann, E. M., Dietlein, T., and Pfeiffer, N. (2020). The Diagnosis and Treatment of Glaucoma. Dtsch. Arztebl. Int. 117, 225-234.

Schweppe, D. K., Harding, C., Chavez, J. D., Wu, X., Ramage, E., Singh, P. K., et al. (2015). Host-Microbe Protein Interactions During Bacterial Infection. Chem. Biol. 22, 1521-1530. doi: 10.1016/j.chembiol.2015.09.015

Shakya, M., Lo, C. C., and Chain, P. S. G. (2019). Advances and Challenges in Metatranscriptomic Analysis. Front. Genet. 10, 904. doi: 10.3389/fgene.2019.00904 Sheehan, D., Moran, C., and Shanahan, F. (2015). The Microbiota in Inflammatory Bowel Disease. J. Gastroenterol. 50, 495-507. doi: 10.1007/s00535-015-1064-1

Shi, Z., Li, S. K., Charoenputtakun, P., Liu, C. Y., Jasinski, D., and Guo, P. (2018). RNA Nanoparticle Distribution and Clearance in the Eye After Subconjunctival Injection With and Without Thermosensitive Hydrogels. J. Control Release 270, 14-22. doi: 10.1016/j.jconrel.2017.11.028

Shobar, R. M., Velineni, S., Keshavarzian, A., Swanson, G., DeMeo, M. T., Melson, J. E., et al. (2016). The Effects of Bowel Preparation on Microbiota-Related Metrics Differ in Health and in Inflammatory Bowel Disease and for the Mucosal and Luminal Microbiota Compartments. Clin. Transl. Gastroenterol. 7, e143. doi: 10.1038/ctg.2015.54

Singh, P. K., Donovan, D. M., and Kumar, A. (2014). Intravitreal Injection of the Chimeric Phage Endolysin Ply187 Protects Mice From Staphylococcus Aureus Endophthalmitis. Antimicrob. Agents Chemother. 58, 4621-4629. doi: 10.1128/ AAC.00126-14 
Skrzypecki, J., Żera, T., and Ufnal, M. (2018). Butyrate, a Gut Bacterial Metabolite, Lowers Intraocular Pressure in Normotensive But Not in Hypertensive Rats. J. Glaucoma 27, 823-827. doi: 10.1097/IJG.0000000000001025

Skrzypecki, J., Izdebska, J., Kaminska, A., Badowska, J., Przybek-Skrzypecka, J., Bombuy, J., et al. (2021). Glaucoma Patients Have an Increased Level of Trimethylamine, a Toxic Product of Gut Bacteria, in the Aqueous Humor: A Pilot Study. Int. Ophthalmol. 41, 341-347. doi: 10.1007/s10792-020-01587-y

Smith, P. M., Howitt, M. R., Panikov, N., Michaud, M., Gallini, C. A., Bohlooly, Y. M., et al. (2013). The Microbial Metabolites, Short-Chain Fatty Acids, Regulate Colonic Treg Cell Homeostasis. Science 341, 569-573. doi: 10.1126/science.1241165

Stapleton, F., Keay, L. J., Sanfilippo, P. G., Katiyar, S., Edwards, K. P., and Naduvilath, T. (2007). Relationship Between Climate, Disease Severity, and Causative Organism for Contact Lens-Associated Microbial Keratitis in Australia. Am. J. Ophthalmol. 144, 690-698. doi: 10.1016/j.ajo.2007.06.037

Stein-Streilein, J. (2008). Immune Regulation and the Eye. Trends Immunol. 29, 548-554. doi: 10.1016/j.it.2008.08.002

St Leger, A. J., Desai, J. V., Drummond, R. A., Kugadas, A., Almaghrabi, F., Silver, P., et al. (2017). An Ocular Commensal Protects Against Corneal Infection by Driving an Interleukin-17 Response From Mucosal $\gamma \delta$ T Cells. Immunity 47, 148-158.e145. doi: 10.1016/j.immuni.2017.06.014

Sun, N., Hu, H., Wang, F., Li, L., Zhu, W., Shen, Y., et al. (2021). Antibiotic-Induced Microbiome Depletion in Adult Mice Disrupts Blood-Brain Barrier and Facilitates Brain Infiltration of Monocytes After Bone-Marrow Transplantation. Brain Behav. Immun. 92, 102-114. doi: 10.1016/j.bbi.2020.11.032

Sun, M., Wu, W., Liu, Z., and Cong, Y. (2017). Microbiota Metabolite Short Chain Fatty Acids, GPCR, and Inflammatory Bowel Diseases. J. Gastroenterol. 52, 18. doi: 10.1007/s00535-016-1242-9

Szymula, A., Rosenthal, J., Szczerba, B. M., Bagavant, H., Fu, S. M., and Deshmukh, U. S. (2014). T Cell Epitope Mimicry Between Sjögren's Syndrome Antigen A (SSA)/Ro60 and Oral, Gut, Skin and Vaginal Bacteria. Clin. Immunol. 152, 1-9. doi: 10.1016/j.clim.2014.02.004

Tadayoni, R. (2014). Choroidal Neovascularization Induces Retinal Edema and its Treatment Addresses This Problem. J. Ophthalmic. Vis. Res. 9, 405-406. doi: 10.4103/2008-322X.150799

Tai, N., Wong, F. S., and Wen, L. (2015). The Role of Gut Microbiota in the Development of Type 1, Type 2 Diabetes Mellitus and Obesity. Rev. Endocr. Metab. Disord. 16, 55-65. doi: 10.1007/s11154-015-9309-0

Taurog, J. D., Richardson, J. A., Croft, J. T., Simmons, W. A., Zhou, M., FernandezSueiro, J. L., et al. (1994). The Germfree State Prevents Development of Gut and Joint Inflammatory Disease in HLA-B27 Transgenic Rats. J. Exp. Med. 180, 2359-2364. doi: 10.1084/jem.180.6.2359

The Human Microbiome Project Consortium (2012). Structure, Function and Diversity of the Healthy Human Microbiome. Nature 486, 207-214. doi: 10.1038 /nature11234

Todokoro, D., Eguchi, H., Suzuki, T., Suzuki, M., Nakayama-Imaohji, H., Kuwahara, T., et al. (2018). Genetic Diversity and Persistent Colonization of Enterococcus Faecalis on Ocular Surfaces. Jpn J. Ophthalmol. 62, 699-705. doi: $10.1007 /$ s10384-018-0630-5

Trujillo-Vargas, C. M., Schaefer, L., Alam, J., Pflugfelder, S. C., Britton, R. A., and de Paiva, C. S. (2020). The Gut-Eye-Lacrimal Gland-Microbiome Axis in Sjögren Syndrome. Ocul. Surf. 18, 335-344. doi: 10.1016/j.jtos.2019.10.006

Turnbaugh, P. J., Ridaura, V. K., Faith, J. J., Rey, F. E., Knight, R., and Gordon, J. I. (2009). The Effect of Diet on the Human Gut Microbiome: A Metagenomic Analysis in Humanized Gnotobiotic Mice. Sci. Transl. Med. 1, 6ra14. doi: $10.1126 /$ scitranslmed. 3000322

Vercelli, D. (2021). Microbiota and Human Allergic Diseases: The Company We Keep. Curr. Opin. Immunol. 72, 215-220. doi: 10.1016/j.coi.2021.06.002

Vieira, S. M., Hiltensperger, M., Kumar, V., Zegarra-Ruiz, D., Dehner, C., Khan, N., et al. (2018). Translocation of a Gut Pathobiont Drives Autoimmunity in Mice and Humans. Science 359, 1156-1161. doi: 10.1126/science.aar7201

Vignoli, A., Ghini, V., Meoni, G., Licari, C., Takis, P. G., Tenori, L., et al. (2019). High-Throughput Metabolomics by 1D NMR. Angew. Chem. Int. Ed. Engl. 58, 968-994. doi: 10.1002/anie.201804736

Viladomiu, M., Kivolowitz, C., Abdulhamid, A., Dogan, B., Victorio, D., Castellanos, J. G., et al. (2017). IgA-Coated E. Coli Enriched in Crohn's Disease Spondyloarthritis Promote T(H)17-Dependent Inflammation. Sci. Transl. Med. 9, eaaf9655.

Wakefield, D., Montanaro, A., and McCluskey, P. (1991). Acute Anterior Uveitis and HLA-B27. Surv. Ophthalmol. 36, 223-232. doi: 10.1016/0039-6257(91)90005-Z
Walter, J., Armet, A. M., Finlay, B. B., and Shanahan, F. (2020). Establishing or Exaggerating Causality for the Gut Microbiome: Lessons From Human Microbiota-Associated Rodents. Cell 180, 221-232. doi: 10.1016/ j.cell.2019.12.025

Wang, J., Gao, Y., and Zhao, F. (2016). Phage-Bacteria Interaction Network in Human Oral Microbiome. Environ. Microbiol. 18, 2143-2158. doi: 10.1111/ 1462-2920.12923

Wang, C., Zaheer, M., Bian, F., Quach, D., Swennes, A. G., Britton, R. A., et al. (2018). Sjögren-Like Lacrimal Keratoconjunctivitis in Germ-Free Mice. Int. J. Mol. Sci. 19, 565. doi: 10.3390/ijms19020565

Weinbauer, M. G. (2004). Ecology of Prokaryotic Viruses. FEMS Microbiol. Rev. 28, 127-181. doi: 10.1016/j.femsre.2003.08.001

Weinstein, J. E., and Pepple, K. L. (2018). Cytokines in Uveitis. Curr. Opin. Ophthalmol. 29, 267-274. doi: 10.1097/ICU.0000000000000466

Wen, X., Miao, L., Deng, Y., Bible, P. W., Hu, X., Zou, Y., et al. (2017). The Influence of Age and Sex on Ocular Surface Microbiota in Healthy Adults. Invest. Ophthalmol. Vis. Sci. 58, 6030-6037. doi: 10.1167/iovs.17-22957

Wu, T., Mitchell, B., Carothers, T., Coats, D., Brady-McCreery, K., Paysse, E., et al. (2003). Molecular Analysis of the Pediatric Ocular Surface for Fungi. Curr. Eye Res. 26, 33-36. doi: 10.1076/ceyr.26.1.33.14253

Xiong, W., Giannone, R. J., Morowitz, M. J., Banfield, J. F., and Hettich, R. L. (2015). Development of an Enhanced Metaproteomic Approach for Deepening the Microbiome Characterization of the Human Infant Gut. J. Proteome Res. 14, 133-141. doi: 10.1021/pr500936p

Yamazaki, T., Suzuki, H., Yamada, S., Ohshio, K., Sugamata, M., Yamada, T., et al. (2020). Lactobacillus Paracasei KW3110 Suppresses Inflammatory StressInduced Premature Cellular Senescence of Human Retinal Pigment Epithelium Cells and Reduces Ocular Disorders in Healthy Humans. Int. J. Mol. Sci. 21 (14), 5091. doi: 10.3390/ijms21145091

Yanagisawa, N., Ueshiba, H., Abe, Y., Kato, H., Higuchi, T., and Yagi, J. (2018). Outer Membrane Protein of Gut Commensal Microorganism Induces Autoantibody Production and Extra-Intestinal Gland Inflammation in Mice. Int. J. Mol. Sci. 19, 3241. doi: 10.3390/ijms19103241

Yang, P., Wan, W., Du, L., Zhou, Q., Qi, J., Liang, L., et al. (2018). Clinical Features of HLA-B27-Positive Acute Anterior Uveitis With or Without Ankylosing Spondylitis in a Chinese Cohort. Br. J. Ophthalmol. 102, 215-219. doi: 10.1136/ bjophthalmol-2016-309499

Ye, Z., Wu, C., Zhang, N., Du, L., Cao, Q., Huang, X., et al. (2020). Altered Gut Microbiome Composition in Patients With Vogt-Koyanagi-Harada Disease. Gut Microbes 11, 539-555. doi: 10.1080/19490976.2019.1700754

Ye, Z., Zhang, N., Wu, C., Zhang, X., Wang, Q., Huang, X., et al. (2018). A Metagenomic Study of the Gut Microbiome in Behcet's Disease. Microbiome 6, 135. doi: 10.1186/s40168-018-0520-6

Yuan, F., Wang, M., Jin, K., and Xiang, M. (2021). Advances in Regeneration of Retinal Ganglion Cells and Optic Nerves. Int. J. Mol. Sci. 22, 4616. doi: 10.3390/ ijms 22094616

Zaidi, T. S., Zaidi, T., and Pier, G. B. (2018). Antibodies to Conserved Surface Polysaccharides Protect Mice Against Bacterial Conjunctivitis. Invest. Ophthalmol. Vis. Sci. 59, 2512-2519. doi: 10.1167/iovs.18-23795

Zeng, H., and Chi, H. (2015). Metabolic Control of Regulatory T Cell Development and Function. Trends Immunol. 36, 3-12. doi: 10.1016/j.it.2014.08.003

Zeng, J., Liu, H., Liu, X., and Ding, C. (2015). The Relationship Between Helicobacter Pylori Infection and Open-Angle Glaucoma: A Meta-Analysis. Invest. Ophthalmol. Vis. Sci. 56, 5238-5245. doi: 10.1167/iovs.15-17059

Zhang, M., Chu, Y., Mowery, J., Konkel, B., Galli, S., Theos, A. C., et al. (2018). Pgc-1 $\alpha$ Repression and High-Fat Diet Induce Age-Related Macular Degeneration-Like Phenotypes in Mice. Dis. Model. Mech. 11, dmm032698. doi: $10.1242 / \mathrm{dmm} .032698$

Zhang, X., Deeke, S. A., Ning, Z., Starr, A. E., Butcher, J., Li, J., et al. (2018). Metaproteomics Reveals Associations Between Microbiome and Intestinal Extracellular Vesicle Proteins in Pediatric Inflammatory Bowel Disease. Nat. Commun. 9, 2873. doi: 10.1038/s41467-018-05357-4

Zhang, X., Li, L., Butcher, J., Stintzi, A., and Figeys, D. (2019). Advancing Functional and Translational Microbiome Research Using Meta-Omics Approaches. Microbiome 7, 154. doi: 10.1186/s40168-019-0767-6

Zhang, Y., Li, C. X., and Zhang, X. Z. (2021). Bacteriophage-Mediated Modulation of Microbiota for Diseases Treatment. Adv. Drug Deliv. Rev. 5, 113856. doi: 10.1016/j.addr.2021.113856 
Zhao, F., Zhang, D., Ge, C., Zhang, L., Reinach, P. S., Tian, X., et al. (2020). Metagenomic Profiling of Ocular Surface Microbiome Changes in Meibomian Gland Dysfunction. Invest. Ophthalmol. Vis. Sci. 61, 22. doi: 10.1167/iovs.61.8.22

Zhou, Y., Holland, M. J., Makalo, P., Joof, H., Roberts, C. H., Mabey, D. C., et al. (2014). The Conjunctival Microbiome in Health and Trachomatous Disease: A Case Control Study. Genome Med. 6, 99. doi: 10.1186/s13073-014-0099-x

Zhou, J., Yang, J., Dai, M., Lin, D., Zhang, R., Liu, H., et al. (2020). A Combination of Inhibiting Microglia Activity and Remodeling Gut Microenvironment Suppresses the Development and Progression of Experimental Autoimmune Uveitis. Biochem. Pharmacol. 180, 114108. doi: 10.1016/j.bcp.2020.114108

Zilliox, M. J., Gange, W. S., Kuffel, G., Mores, C. R., Joyce, C., de Bustros, P., et al. (2020). Assessing the Ocular Surface Microbiome in Severe Ocular Surface Diseases. Ocul. Surf. 18, 706-712. doi: 10.1016/j.jtos.2020.07.007

Zinkernagel, M. S., Zysset-Burri, D. C., Keller, I., Berger, L. E., Leichtle, A. B., Largiadèr, C. R., et al. (2017). Association of the Intestinal Microbiome With the Development of Neovascular Age-Related Macular Degeneration. Sci. Rep. 7, 40826. doi: 10.1038/srep40826

Zysset-Burri, D. C., Schlegel, I., Lincke, J. B., Jaggi, D., Keller, I., Heller, M., et al. (2021). Understanding the Interactions Between the Ocular Surface
Microbiome and the Tear Proteome. Invest. Ophthalmol. Vis. Sci. 62, 8. doi: $10.1167 /$ iovs.62.10.8

Conflict of Interest: The authors declare that the research was conducted in the absence of any commercial or financial relationships that could be construed as a potential conflict of interest.

Publisher's Note: All claims expressed in this article are solely those of the authors and do not necessarily represent those of their affiliated organizations, or those of the publisher, the editors and the reviewers. Any product that may be evaluated in this article, or claim that may be made by its manufacturer, is not guaranteed or endorsed by the publisher.

Copyright (c) $2021 \mathrm{Xue}, \mathrm{Li}, \mathrm{Zou}, \mathrm{Zou}$ and Wei. This is an open-access article distributed under the terms of the Creative Commons Attribution License (CC BY). The use, distribution or reproduction in other forums is permitted, provided the original author(s) and the copyright owner(s) are credited and that the original publication in this journal is cited, in accordance with accepted academic practice. No use, distribution or reproduction is permitted which does not comply with these terms. 